NBER WORKING PAPER SERIES

\title{
MONETARY SOVEREIGNTY, EXCHANGE RATES, AND CAPITAL CONTROLS: \\ THE TRILEMMA IN THE INTERWAR PERIOD
}

\author{
Maurice Obstfeld \\ Jay C. Shambaugh \\ Alan M. Taylor \\ Working Paper 10393 \\ http://www.nber.org/papers/w10393 \\ NATIONAL BUREAU OF ECONOMIC RESEARCH \\ 1050 Massachusetts Avenue \\ Cambridge, MA 02138 \\ March 2004
}

Obstfeld gratefully acknowledges the support of the Class of 1958 chair at Berkeley. Taylor gratefully acknowledges the support of the Chancellor's Fellowship at the University of California, Davis. All three authors thank Julian di Giovanni and Ahmed Rahman for excellent research assistance, and are grateful to Robert Flood and Hélène Rey for their helpful comments. The views expressed herein are those of the author and not necessarily those of the National Bureau of Economic Research.

(C2004 by Maurice Obstfeld, Jay C. Shambaugh, and Alan M. Taylor. All rights reserved. Short sections of text, not to exceed two paragraphs, may be quoted without explicit permission provided that full credit, including (C) notice, is given to the source. 
Monetary Sovereignty, Exchange Rates, and Capital Controls:

The Trilemma in the Interwar Period

Maurice Obstfeld, Jay C. Shambaugh, and Alan M. Taylor

NBER Working Paper No. 10393

March 2004

JEL No. F33, F41, F42, N10

\section{ABSTRACT}

The interwar period was marked by the end of the classical gold standard regime and new levels of macroeconomic disorder in the world economy. The interwar disorder often is linked to policies inconsistent with the constraint of the open-economy trilemma - the inability of policymakers simultaneously to pursue a fixed exchange rate, open capital markets, and autonomous monetary policy. The first two objectives were linchpins of the pre-1914 order. As increasingly democratic polities faced pressures to engage in domestic macroeconomic management, however, either currency pegs or freedom of capital movements had to yield. This historical analytic narrative is compelling - with significant ramifications for today's world, if true - but empirically controversial. We apply theory and empirics to the interwar data and find strong support for the logic of the trilemma. Thus, an inability to pursue consistent policies in a rapidly changing political and economic environment appears central to an understanding of the interwar crises, and the same constraints still apply today.

Maurice Obstfeld

Department of Economics

549 Evans Hall \#3880

University of California

Berkeley, CA 94720-3880

and NBER

obstfeld@econ.berkeley.edu

Jay C. Shambaugh

Department of Economics

309 Rockefeller Hall

Dartmouth College

Hanover, NH 03755

jay.c.shambaugh@dartmouth.edu

\author{
Alan M. Taylor \\ Department of Economics \\ University of California \\ One Shields Avenue \\ Davis, CA 95616-8578 \\ and NBER \\ amtaylor@ucdavis.edu
}


In the present era of globalization, one of the most difficult challenges for governments - and for those who advise them - is to understand the constraints under which policies must be designed in a world of increasing economic interdependence. Nowhere are these constraints more pressing than in the arena of monetary policy design in open economies, where the recent spate of economic crises in developing countries, from Mexico in 1994 to East Asia in 1997 to Argentina in 2001, highlighted the costs to be paid when the exchange rate regime unravels. In this paper we place the current quandary in a longer run context, and ask what lessons history has for contemporary problems. Our approach brings together theory, empirics, and history.

The theoretical foundation of this paper casts the choices faced by policymakers in terms of the classic macroeconomic trilemma: the idea that of the three policy objectives of a fixed exchange rate, open capital markets, and autonomous monetary policy; only two can be mutually consistent and, hence, tenable as stable features of the policy regime. The intuition is simple: when a country credibly and permanently pegs its exchange rate to some base country, and when capital is freely mobile, simple interest parity pins down the domestic interest rate, forcing it to be equal to the interest rate in the base country. We do not study what might be driving the intent of the authorities to manipulate nominal interest rates in the short run, but we take as given their desire to engage in active macroeconomic management over the business cycle and their belief that, due to shortrun nominal rigidities, such intervention might be effective.

We will also take it as given-even uncontroversial - that the defining role of a sovereign monetary authority is that it will exercise such powers, when feasible and desirable, and this will affect liquidity, and hence interest rates, at the short end of the market. Some deeper questions intrude, however, especially with regard to feasibility and desirability. On feasibility, in contrast to the stark prescriptions of the trilemma, we know that intervention can be more continuous than dichotomous, sometimes as a result of authorities' decisions not to peg to a fixed rate, but instead to limit exchange rate movements to a band or "target zone." As has been recognized in the literature at least since the writings of Goschen (1861), this can leave some wiggle room for monetary policy - but how much? On desirability, we also have to be careful about the intent (or objectives) of policymakers, versus their constraints (or choice set). Under some policy systems, such as the gold standard, intent was not really a matter of debate in theory, although economic historians have noted that substantial deviations were witnessed in practice (Bloomfield, 1959; and Scammell, 1965). Under alternative systems, such as inflation targeting or other nominal anchors, authorities may have varying degrees of freedom depending on the regime in place, and depending on the regime of the partner country. Thus convergence, or divergence, from international monetary regimes or operating rules - a function of history, politics, and ideology - may lead to greater or lesser degrees of synchronization in policymakers' actions. 
Our approach to these difficulties is to develop a formal model as a benchmark to guide our interpretation of the empirical findings. Using a target-zone model, one can compute the extent to which policymakers create a divergence between short-term domestic and base-country interest rates under various policy scenarios. Different parameterizations allow such a model to capture both tight pegs (a narrow band) and nonpegs (an infinite band width), as well as varying degrees of activism on the part of policymakers as they seek to smooth out, or reinforce, monetary shocks from abroad.

The goal of the subsequent empirical work is to measure the extent to which changes in the relevant foreign "base" nominal interest rate pass through into the domestic nominal interest rate. The data provide some challenges. Sometimes care is needed to ensure that the correct base country is chosen, because at certain times in history this choice is not necessarily obvious. Furthermore, the status of a country with respect to the fixity of its exchange rate against any base currency is not always clear. Another difficulty arises from the near-nonstationarity of nominal interest rates in many historical periods. That feature of the data narrows our choice of techniques for both time series and panel estimation. With these problems addressed, however, the empirical method allows us to concentrate on the central predictions of the trilemma. To what extent do countries that peg and have open capital markets lose their monetary sovereignty? And do they recoup it when they resolve the trilemma in other ways - either by allowing the exchange rate to float, or by imposing capital controls? By dividing our sample according to exchange rate regime and capital control criteria, we can examine these questions.

The trilemma is not necessarily an easy proposition to test, but we view our approach as one of the more direct ways to explore its validity. Previous empirical tests of the trilemma have produced mixed results. Often the test has been indirect, as with the literature on the so-called "exchange rate disconnect" (Baxter and Stockman, 1989; and Flood and Rose, 1995). These authors saw very little difference in the statistical properties of real and nominal economic fluctuations in fixed versus floating rate episodes, except for the volatility and comovement of real and nominal exchange rates. As a corollary it could be inferred that the trilemma tradeoffs might not impinge so tightly. Yet such an inference would clearly depend on additional maintained assumptions, in particular about the horizon over which autonomy can be presumed to have an effect. Further, since the data used for these analyses was of low frequency, it could very well understate the ability of monetary authorities to exert some highfrequency autonomy, even if they are subject to other constraints, such as real interest rate equality, at longer horizons. ${ }^{1}$

A more direct approach to testing the trilemma was taken by Rose (1996) who compared the predictions of a monetary model of exchange rates, based on money

\footnotetext{
${ }^{1}$ Indeed, the one "robust result" cited by Flood and Rose is a negative relationship between exchange rate and output variability (Flood and Rose, 1995, p. 18). That pattern is consistent with a role for exchange rate flexibility in dampening output fluctuations.
} 
aggregates and outputs, with actual exchange rate movements, conditional on capital controls and the exchange rate regime. His results were somewhat consistent with the trilemma, but still weak. It could be argued that one source of weakness was the use of the monetary model, which seems to perform poorly at higher frequencies, due to unstable money demand, and which is therefore unable cleanly to capture the high frequency content of the trilemma. A natural alternative is to measure monetary policy not by a quantity, money stocks, but by a price, namely the actual instrument used by most central banks to impose their policy - the short-term interest rate. Ours is one of several recent studies to follow this tack (Frankel, Schmukler, and Servén, 2002; Obstfeld, Shambaugh, and Taylor, 2004; and Shambaugh, 2004).

We choose to bring these theoretical and empirical tools to bear on one of the most turbulent periods in the history of the international macroeconomy - the interwar period. In the next section we explore the history of that period, where the narratives tell of a crisis in which the implications of the trilemma were suddenly more apparent than ever before. Subsequent sections discuss our theoretical simulations, describe the data we employ, and present the empirical results. A concluding section sums up the lessons learned and their relevance today.

\section{Trilemma in the Interwar Period}

After introducing our footholds in theory and empirics, we now turn to history and the interwar period, which is the object of study in this paper. The period's relevance is clear: arguably it was in this epoch that the trilemma forcefully made its presence felt for the first time in the great debate over the political economy of macroeconomics. For that reason, the trilemma idea resonates strongly with economic historians, who tend to understand the evolution of the global macroeconomic order in those terms. In the interwar period, all the key ingredients of the trilemma came into collision (Eichengreen, 1996; and Obstfeld and Taylor, 1998, 2004).

In 1913, the ideology of the classical gold standard still held sway, and international capital market integration had reached its zenith, leaving the authorities with little room for maneuver. The rise of more democratic polities led policymakers to seek greater autonomy than the old "rules of the game" permitted. Conventional wisdom argues that such a combination of inconsistent elements set the gold standard up for its swift demise following a brief reconstruction in the 1920s, a key part of the wider collapse of globalization seen during the interwar years (Temin, 1989; and James, 2001). Some have further argued that this crisis reflected a fundamental conflict between economic globalization, or at least its macroeconomic manifestation in the gold standard, and the advance of democracy, a tension that would perhaps henceforth place limits on the role of markets under the modern nation-state, although the recent so-called return to globalization has seemingly reversed that trend (Polanyi, 1944; Yergin and Stanislaw, 
1998; Lindsey, 2002; and Tortella, 2003). This is the history, therefore, not of a farremoved past but a close precursor of the present, and the same trilemma clearly has relevance for the choices facing policymakers today. Once again, capital markets are increasingly fluid, an air of experimentation surrounds exchange rate regime choice, and the loss of monetary sovereignty is an issue of burning interest, especially to emergingmarket countries.

Thus, the interwar period stands as a defining moment in the history of modern political economy and macroeconomics, and the trilemma was the issue at the very center of events. The historical record provides plenty of examples and anecdotes consistent with this story. Witness the heated debate over gold resumption at par in Britain, pitting Keynes against conventional opinion, as general labor unrest simmered in the background; or, under conditions of equal or greater social foment, consider the tortured compromises by French politicians in the run up to Poincaré's resumption at a devalued parity, and the continuing policy uncertainty as France clung to gold until 1936. Yet, despite all of this suggestive evidence, we are unaware of any research that formally and directly tests for the presence of the trilemma, and examines its potency, in the macroeconomic crucible of the interwar years.

Unfortunately, this is to some degree understandable given the chaotic nature of the period. Serious empirical work of the kind we envisage requires high-frequency data collection for interest rates and clear records of the capital control and exchange rate regimes for each country. The task is daunting for the years between the wars, as data can be collected only with difficulty and with substantial noise. Regime definition is often imprecise and certainly volatile. Many countries changed their peg and capital control status several times. Some countries were off gold but really "shadowing" the gold standard in a desperate attempt eventually to rejoin. Capital control policies varied by country in their degree of strictness. Our own work has previously examined the trilemma empirically in the pre-1914 and post-1945 periods, where the empirical challenges are somewhat fewer (Obstfeld, Shambaugh, and Taylor, 2004). We have since, however, constructed an interwar database that allows us to put the trilemma to the test at perhaps its most critical historical moment.

Looking on the bright side, the extreme variation in conditions during the interwar sample period is, of course, good news from the econometric standpoint. Whereas our previous work compared economic experiences separated by many decades, and sometimes a century or more, the interwar period supplies all the variation we could hope for in the space of ten or fifteen years. In that brief window, fixes and floats, controls and free markets were all tried here and there. We therefore find ample power to identify the effects we study, although sometimes the extremely short duration of peg and float episodes makes univariate time-series analysis difficult. The interwar period also follows hard on the heels of an ideal benchmark era against which we can compare our results - the classical pre-1914 gold standard. Accordingly, we shall refer back to results 
for that period as a basis for judging the behavior of the interwar regimes. Along the way, we also gain an opportunity to consider some related hypotheses, for example, the muchdiscussed switch of the world financial center from London to New York after World War I, considered essential to the hegemony theory of an evolution from a British- to a U.S.led world order (Kindleberger, 1986).

The central aim, however, is to test the power of the trilemma as an explanatory tool. To lay the groundwork for that test, we now turn to some important theoretical considerations that help buttress our econometric approach and subsequent interpretations of the results.

\section{Empirical Methodology and Rationale}

The starting point for our econometric analysis is a panel regression of the form

$$
\Delta R_{i t}=\beta \Delta R_{b i t}+u_{i t}
$$

where $R_{i t}$ is the nominal interest rate in country $i$ on date $t, R_{b i t}$ is the interest rate in the "base" country, and $u_{i t}$ is a random shock. ${ }^{2}$ Under perfect international capital mobility and an exchange rate credibly pegged with a zero fluctuation band, we would expect to find ordinary least squares (OLS) estimates of $\hat{\beta}=1$ and $R^{2}=1$. In practice, however, the actual estimates differ from this hypothetical benchmark case, and we wish to know if there are systematic differences in the size of $\hat{\beta}$ between pegged exchange rate regimes and nonpegs. Our claim is that such divergences inform us about the scope for interest rate management, and therefore for monetary policy independence, under alternative exchange rate regimes. As an alternative way to measure the impact of a peg on the sensitivity of domestic to foreign interest rates, we pool data from peg and nonpeg regimes and look at the magnitude of $\hat{\beta}_{2}$ in the regression

$$
\Delta R_{i t}=\beta_{1} \Delta R_{b i t}+\beta_{2}\left(\Delta R_{b i t} \times P E G_{i t}\right)+u_{i t}
$$

where $P E G_{i t}$ takes the value 1 if country $i$ pegs to the base currency at time $t$ and 0 otherwise.

We focus our theoretical discussion on the key slope coefficient $\beta$ in equation (1), though we also consider the fit of that equation in our empirical results. A convenient

\footnotetext{
${ }^{2}$ Variants of this methodology are followed also the precursor papers by Frankel, Schmukler, and Servén (2002), Obstfeld, Shambaugh, and Taylor (2004), and Shambaugh (2004). We omit fixed effects from the preceding equation on the grounds that deterministic trends in nominal interest rates are implausible; and, in practice, when we include such fixed effects they are estimated to be indistinguishable from zero.
} 
starting point for interpreting estimates of equation (1) is the generalized uncovered interest parity relationship

$$
R=R_{b}+\varepsilon+v
$$

where $\varepsilon$ is the expected depreciation rate of the domestic currency (over a horizon corresponding to that of the interest rates $R$ and $R_{b}$ ) and $v$ is a random, mean-zero, excess return or risk premium that, for convenience, we take to be exogenous. Given the model of equation (3), the OLS estimate of $\beta$ in the difference regression (1) satisfies

$$
\begin{gathered}
\operatorname{plim} \hat{\beta}_{\text {DIFFS }}=\operatorname{plim} \frac{\sum_{t}\left(\Delta R_{t} \bullet \Delta R_{b t}\right)}{\sum_{t}\left(\Delta R_{b t}\right)^{2}}=1+\operatorname{plim} \frac{\frac{1}{T} \sum_{t}\left(\Delta \varepsilon_{t} \bullet \Delta R_{b t}\right)}{\frac{1}{T} \sum_{t}\left(\Delta R_{b t}\right)^{2}} \\
=1+\rho\left(\Delta \varepsilon_{t}, \Delta R_{b t}\right) \frac{\sigma\left(\Delta \varepsilon_{t}\right)}{\sigma\left(\Delta R_{b t}\right)}
\end{gathered}
$$

where $\rho$ is a correlation coefficient, $\sigma$ is a standard deviation, and $T$ is sample size. The second term on the right-hand side above captures the average response of exchange rate expectations to changes in the base interest rate. Under interest parity, if a rise in the foreign base interest rate is accompanied by a smaller absolute rise in the domestic interest - as would be the case under a system of domestic interest rate smoothing by the monetary authority-then the expected rate of currency depreciation, $\varepsilon$, must simultaneously fall. This could be accomplished by allowing the domestic currency to depreciate sufficiently in the foreign exchange market to induce a higher expected rate of future appreciation (that is, a lower expected rate of future depreciation). In that case, the average $\Sigma_{t}\left(\Delta \varepsilon_{t} \Delta R_{b t}\right) / T$ is negative for large enough $T$, as is the correlation coefficient $\rho\left(\Delta \varepsilon_{t}, \Delta R_{b t}\right)$, and $\hat{\beta}<1$. Alternatively, were the home monetary authority to reinforce the effect of foreign interest shocks, one would expect $\hat{\beta}>1$. Thus, the coefficient $\beta$ measures the extent to which domestic monetary policy has (and uses) the scope to respond to foreign interest rate shocks.

An alternative specification would be the analog of equation (1) in interest rate levels rather than differences,

$$
R_{i t}=\alpha+\beta R_{b i t}+\eta_{i t}
$$

Such a strategy seems inadvisable in light of the persistence of nominal interest rates in our data. For the interwar period, the monthly series of U.S. interest rates displays an autocorrelation coefficient of 0.99 in monthly data, and for the vast majority of other 
interest rates in our sample the presence of a unit root cannot be rejected statistically. ${ }^{3}$ Thus, the assumption of a unit root in interest rates is a good approximation to the data.

Under a unit root, however, estimation in levels of interest rates yields

$$
\operatorname{plim} \hat{\beta}_{\text {LEVELS }}=\operatorname{plim} \frac{\sum_{t}\left(R_{t} \bullet R_{b t}\right)}{\sum_{t}\left(R_{b t}\right)^{2}}=1+\operatorname{plim} \frac{\sum_{t}\left(\varepsilon_{t} \bullet R_{b t}\right)}{\sum_{t}\left(R_{b t}\right)^{2}}=1,
$$

assuming the expected depreciation rate is statistically stationary. Because the stochastic trends in the interest rates dominate, levels estimates are not well suited to yield information about interest rate independence. If international interest rates are not cointegrated, the spurious regression problem stressed by Shambaugh (2004) can arise. In the data, we find that the residual terms in equation (1) are approximately serially uncorrelated.

To evaluate these claims, as well as to aid in interpreting the empirical results, we perform Monte Carlo experiments using simulated data based on a formal model of exchange rate target zones. The basic model comes from Krugman (1991) and has been extended by Flood and Garber (1991), Froot and Obstfeld (1991), Svensson (1991), and others. To generate interest rates of noninstantaneous maturity, we utilize Svensson's (1991) account of the term structure of interest rates within a target zone. We compare the results of interest rate regressions under a narrow target zone (bands of \pm 1 percent) and a freely floating exchange rate.

It is helpful to give a brief description of the model that we use in these simulations. ${ }^{4}$ The time- $t$ log exchange rate, $e(t)$, is defined as the home price of foreign currency. It is determined by the forward-looking pricing equation

$$
e(t)=x(t)+\eta \frac{\mathrm{E}_{t}\{\mathrm{~d} e(t)\}}{\mathrm{d} t}
$$

where $x(t)$ is a "fundamental" economic variable driving currency value (for example, the home less the foreign money supply) and $\eta>0$. The fundamental $x$ follows a mean reverting process of form

$$
\mathrm{d} x=-\xi x \mathrm{~d} t+\sigma \mathrm{d} z
$$

\footnotetext{
${ }^{3}$ In contrast, under the pre-1914 gold standard, nominal interest rates appear stationary. Apparent nonstationarity is the rule after World War II, as during the interwar period.

${ }^{4}$ A more detailed description of the model and methodology can be found in Obstfeld, Shambaugh, and Taylor (2004).
} 
where $\mathrm{d} z$ is Gaussian noise. ${ }^{5}$ Under these assumptions, and an allowable (reflecting) fluctuation band $[\underline{e}, \bar{e}]$ for the exchange rate, there is a unique price solution $e=s(x)$, from which the expected depreciation rate of the domestic currency,

$$
\frac{\mathrm{E}_{t}\{\mathrm{~d} e\}}{\mathrm{d} t}=-\xi x s^{\prime}(x)+\frac{\sigma^{2}}{2} s^{\prime \prime}(x),
$$

follows from Itô's Lemma. ${ }^{6}$

The preceding equation defines an instantaneous expected depreciation rate. The interest rates available for empirical analysis apply, however, to finite maturities. Svensson (1991) shows that when uncovered interest rate parity holds, we can approximate the international interest differential at maturity $m$ by

$$
\delta(m, x)=\frac{f(m, x)-s(x)}{m},
$$

where $f(m, x)$ is the exchange rate expected to prevail after an interval of positive length $m$ has elapsed. ${ }^{7}$ We specify the base foreign interest rate $R_{b}^{m}$ of the relevant maturity to follow a random walk, constrained only by a lower bound of zero. In line with equation (3), which incorporates a deviation $v$ from interest parity, the domestic nominal interest rate of maturity $m$ is then modeled as

$$
R^{m}=R_{b}^{m}+\delta(m, x)+v
$$

We interpret the error $v$ as an empirical, serially uncorrelated and exogenous departure from the underlying economic model. Svensson (1991) shows how to solve for the term expected depreciation rate $\delta(m, x)$. In our simulations, $R^{m}$ has a lower bound of zero. We further constrain the noise $v$ to preclude pure arbitrage profits in the target zone case (that is, we rule out interest differentials larger than the maximum capital loss allowed by the

\footnotetext{
${ }^{5}$ In Krugman's (1991) original model, $\xi=0$. Under that assumption, however, exchange rates would follow a random walk under a free float, minimizing international interest differentials. To get a better sense for the scope for interest rate independence under a float, we therefore consider the case $\xi>0$ in our simulations, following Froot and Obstfeld (1991).

${ }^{6}$ The exchange rate solution under a free float, such that $[\underline{e}, \bar{e}] \rightarrow[-\propto,+\infty]$, is simply:

$$
e=\frac{x}{1+\eta \xi}
$$

${ }^{7}$ Of course, $f(0, x)=s(x)$. Think of $m$ as a fraction of a year.
} 
bands). That further constraint is necessary when the bands are permanent and fully credible, as we are assuming.

In practice we approximate equation (6) by a discrete-time process sampled at intervals of $h=10$ minutes. The base interest rate's level is generated as a random walk modified by a nonnegativity constraint. Innovations in the base interest rate and the domestic fundamentals are drawn form a bivariate normal distribution. A key parameter in the simulated data is $\rho\left(\Delta z, \Delta R_{b}\right)$, defined as the instantaneous correlation between the innovation in the base interest rate $R_{b i, t}{ }^{m}-R_{b i, t-h}{ }^{m}$ and the innovation in fundamentals, $z_{t}-$ $z_{t-h}$. To interpret $\rho\left(\Delta z, \Delta R_{b}\right)$, think again of $z_{t}-z_{t-h}$ as the innovation in the home less foreign money supply (in logs). In that case, a positive $\rho\left(\Delta z, \Delta R_{b}\right)$ signifies a tendency for domestic money to increase relative to foreign money when the foreign interest rate rises, an outcome that would dampen the response of the home to the foreign interest rate. In contrast, when $\rho\left(\Delta z, \Delta R_{b}\right)=0$ that response is one-for-one, whereas for $\rho\left(\Delta z, \Delta R_{b}\right)<0$, instead of interest rate smoothing by the domestic central bank, we have the opposite: policy action to reinforce the domestic impact of the foreign interest rate movement.

Because expected depreciation $\varepsilon$ is decreasing in the fundamental $x{ }^{8}$, the correlation coefficient $\rho\left(\Delta \varepsilon, \Delta R_{b}\right)$ in equation (4) is an inverse function of $\rho\left(\Delta z, \Delta R_{b}\right)$. As a result, setting $\rho\left(\Delta z, \Delta R_{b}\right)>0$ results in $\rho\left(\Delta \varepsilon, \Delta R_{b}\right)<0$ and, by equation (4), in $\hat{\beta}<1$. Conversely, setting $\rho\left(\Delta z, \Delta R_{b}\right)<0$ yields $\hat{\beta}>1$.

Table 1 shows the mean estimates and dispersion based on 1,000 replications of a 30year history. We consider both a target zone with quite narrow bands $( \pm 1$ percent, that is, $[\underline{e}, \bar{e}]=[-0.01,0.01])$ and a floating regime. ${ }^{9}$ The simulation analysis produces threemonth rates of interest under alternative policy settings of $\rho\left(\Delta z, \Delta R_{b}\right)=0.8,0.5,0$, and $-0.5 .^{10}$

${ }^{8}$ The validity of the last claim follows from both the mean reversion in the fundamentals process and the curvature of the exchange rate solution function, $s(x)$.

${ }^{9}$ We note that a target-zone width of \pm 1 percent corresponds to the Bretton Woods fluctuation bands against the U.S. dollar, and is considerably narrower than the bands that have characterized the European Exchange Rate Mechanisms. A band width of \pm 1 percent also is not far off estimates of the target zone induced by gold points prior to 1914 .

${ }^{10}$ Table 1 reports results for three-month rates because that maturity is typical in our empirical analysis. We examined overnight rates in simulations that are not reported here. At that maturity the international linkage is somewhat weaker, as one would expect, although the differences from the numbers in Table 1 are not huge. For the simulations, we calibrate the annual standard deviation of the innovation in $R_{b}^{m}$ to that in the annual average end-of-month Federal funds rate (1975-2001). We calibrate the annual standard deviation of the innovation in fundamentals, $x$, to that in the annual average end-of-month dollar-mark (starting in 1999, dollar-euro) exchange rate (1975-2001). Finally, we take the standard deviation in the exogenous noise $v$ to be 20 basis points for interest rates expressed on an annual basis. The behavioral parameter $\eta$, the implicit (absolute) interest semi-elasticity of money demand, is set to 4 . At a nominal interest rate of 5 percent per 
For policy regimes ranging from $\rho\left(\Delta z, \Delta R_{b}\right)=0.5$ (partial interest rate smoothing) to $\rho\left(\Delta z, \Delta R_{b}\right)=0.8$ (more aggressive interest rate smoothing), Table 1 shows that the mean slope estimate $\hat{\beta}_{\text {DIFFS }}$ from the differences specification, equation (1), is in a range of 0.7 to 0.5 . An intermediate figure is 0.6 - far below unity despite the rather narrow target zone. In the corresponding floating-rate regimes, $\hat{\beta}_{\text {DIFFS }}$ is considerably below its value in the target-zone cases, suggesting substantially more interest rate independence at the short end. For $\rho\left(\Delta z, \Delta R_{b}\right)=0.8$ the mean estimate is only 0.16 . Nonetheless, for $\rho\left(\Delta z, \Delta R_{b}\right)=$ 0.5 , the mean estimate of $\hat{\beta}_{\text {DIFFS }}=0.46$ under a float remains sizable. As expected, the average measure of fit, $R_{\text {DIFFS }}^{2}$, also varies across regimes with target zones generating a range of 0.13 to 0.20 and floats 0.02 to 0.05 . The fact that these are so far from the predicted value of 1 if there is no smoothing provides important context for the empirical results.

When $\rho\left(\Delta z, \Delta R_{b}\right)=0$, meaning that interest rates are not smoothed at all, the estimate of $\hat{\beta}_{\text {DIFFS }} \approx 1$ reflects that domestic interest rates now are moving basically in tandem with the base rate, under both the target zone and the float. For $\rho\left(\Delta z, \Delta R_{b}\right)=-0.5, \hat{\beta}_{\text {DIFFS }}$ exceeds 1 because foreign interest rate movements are reinforced, not offset, by domestic policy. The effect is stronger under a float than under a target zone. Under a float, the effects of fundamentals on the exchange rate, and hence, the interest rate responses, are not muted by expected intervention at the band edges.

The results of estimating the levels specification, equation (5), are reported in the column of Table 1 labeled $\hat{\beta}_{\text {LEVELS }}$. These results are as expected when the base interest rate, $R_{b i t}$, has a unit root. The levels estimates $\hat{\beta}_{\text {LEVELS }}$ are much closer to unity than $\hat{\beta}_{\text {DIFFs }}$ under all policy settings, and as a result, the estimated differences between the target zone and the float are much less evident than in the less compressed differences estimates. We have experimented with simulated sample periods out to 100 years and find that while the differences estimates remain quite stable, the levels estimates (as one would expect) move markedly in the direction of unity as the sample period is lengthened. The levels estimates obscure the contrasts between regimes in finite samples, and will hide them entirely as the time-series sample grows arbitrarily long. The values of $R_{\text {LEVELS }}^{2}$ are high due to the common trend in foreign and domestic interest rates.

In practice we estimate equation (1) on a panel of annual year-average interest rate changes, so as to minimize international asymmetries caused by different short-term dynamic adjustment patterns to foreign interest rate changes. We pursue an additional estimation strategy, however, that focuses directly on the dynamics of adjustment. If the interest rate data are indeed statistically nonstationary, an error-correction specification can be used to analyze the dynamics of monthly data. In practice one cannot be sure the data are $I(1)$ rather than $I(0)$. To maintain an agnostic view on stationarity, we employ a

year, the implied interest elasticity of money demand would be -0.2 , the value cited by Romer (2001, p. 470). We set $\xi=1.5$. 
technique proposed by Pesaran, Shin, and Smith (2001), henceforth PSS, in which an error-correction form is estimated but different critical values are applied to the $I(1)$ and $I(0)$ cases. ${ }^{11}$ Only when test statistics lie in an intermediate range must inference rely on an assumption about the order of integration.

The PSS technique relies on the specification

$$
\Delta R_{i t}=\alpha+\beta \Delta R_{b i t}+\theta\left(c+R_{i t-1}-\gamma R_{b i, t-1}\right)+u_{i t}
$$

where lags of $\Delta R_{i t}$ and $\Delta R_{b i t}$ are included as necessary and $\gamma$ is a cointegrating coefficient. The significance and absolute magnitude of the coefficient $\theta$, which we expect to be negative, if local interest rates adjust back toward the base rate after a shock, reflect the strength of the adjustment forces. In the monthly data we use, a coefficient of $\theta=-0.5$ would imply a half-life of one month. Other things equal, faster adjustment is an indicator of a less autonomous monetary policy. For nonstationary data we would expect $\gamma=1$, in which case one could impose that equality on the equation before estimating $\theta$.

The final column of Table 1 reports mean simulated values of the estimate $\hat{\theta}$ from equation (7). The estimates average to around -0.2 under a target zone and about -0.1 under a float, with the result fairly insensitive to the extent of short-run interest rate smoothing. The implied half-lives of shocks are under three months for a target zone but roughly seven months for floats.

\section{Data}

\section{Interest Rate Data}

To test the trilemma's predictions, we must describe the different policy options countries are pursuing. As noted above, we view the short-term nominal interest rate as the instrument of a country's monetary policy and the extent of comovement of the local nominal interest rate with a nominal base-country interest rate as an (inverse) expression of monetary policy autonomy.

Our core data are all monthly. Short-term nominal interest rates for 16 countries in the years 1919-38 come from Global Financial Data ((GFD), www.globalfindata.com). In general these data were originally reported in League of Nations sources. The data are listed as "bills" or "banker's bills" (typically of three-months' maturity). We add data for Switzerland, available in the Federal Reserve's Banking and Monetary Statistics (1943). The League of Nations Statistical Yearbooks reported annual averages of monthly interest rates for Chile and Denmark, and we use these data as well. All three added series are market rates of discount. When available in both sources, the GFD interest rate series match almost exactly the data for private discount rates listed in the Federal Reserve's

${ }^{11}$ This technique is also used by Frankel, Schmukler, and Servén (2002). 
Banking and Monetary Statistics. As noted earlier, in the differences regressions, monthly interest rates for a particular year are averaged to yield annual observations. Table 2 lists the countries and data that are available.

All interest rates are expressed in the form $\ln (1+R)$. While this transformation has a trivial impact for moderate interest rates, it does shrink the impact of outliers. In addition, the German hyperinflation is removed to prevent the massive interest rate swings during that relatively short episode from overwhelming the rest of the data. Thus, observations for Germany from 1923-25 are eliminated.

Because we are interested in comovements with the base interest rate, an important choice is that of the center-country or base nominal interest rate. Under typical post-World War II fixed exchange rate regimes, countries have pegged to other countries, thereby revealing their particular bases. In theory, however, a multilateral gold standard regime differs, in that monetary changes in any country affect the system as a whole, and there is symmetric adjustment. More practically, however, one thinks of a de facto center country, namely, Great Britain, even under the pre-1914 gold standard. In contrast to the classical gold standard, though, there is no clear base country for the system as a whole during the interwar years. While the United States returned fully to the gold standard immediately after World War I, it is not clear that the United States was the sole base for the system. Indeed, the U.S. dollar itself did not remain fixed against gold throughout the entire era (Franklin Roosevelt devalued the dollar-gold exchange rate in 1933). Sterling was not convertible into gold for much of the period; Britain remained on gold only for about 77 months, so Britain is not an ideal base country either. France played a major role in the setting of policies because of its successful attempt to amass large quantities of gold reserves, but it did not repeg to gold on a de jure basis until 1928, two years after the Poincaré macroeconomic stabilization, making it an inappropriate choice as a base country early on in the time period that we study. Because the United States and France held the majority of gold reserves, our default procedure is to use the U.S. interest rate for the early and late periods, and a combination of U.S. and French rates for the years France is on a de jure gold standard. ${ }^{12}$ This base interest rate will be referred to below as the gold interest rate. ${ }^{13}$

Due to the lack of a clear center country, we consider a variety of base country interest rates as robustness checks. We checked all cases using the U.S. interest rate alone, as well as considering the British interest rate as the base rate, as a way of checking the

${ }^{12}$ Mouré (2002) discusses how many view France's gold policies as having had a strong impact on the system as a whole. This source also reports that France and the United States had the two largest national gold reserves and that, combined, they held 50 to 60 percent of the world's total stock of gold reserves.

${ }^{13}$ For annual differences regressions, this is simply the average of the change in the U.S. and French rates. For the levels analysis on monthly data, the U.S. rate is used up to 1928, and then that rate is adjusted going forward by the average change in the U.S. and French rates until 1936, after which it is adjusted by changes in the U.S. rate alone. 
assumption that Britain had ceased to be the center country. We also tried varying the base by local country to allow for the fact that, especially after 1931, the system broke down into smaller spheres of influence. We followed the coding that Eichengreen and Irwin (1995) use to describe currency blocs, dividing countries into Sterling countries (Denmark, India, Japan, and Sweden, using Britain as the base), Gold Bloc countries (Belgium, Italy, Netherlands, and Switzerland, using France as the base), Reichsmark countries (Austria, Bulgaria, Czechoslovakia, Hungary, and Romania, using Germany as the base), and other countries (China and Chile, using the United States as base). ${ }^{14}$ While the cross-base comparisons are discussed below, we feel in general that the gold interest rate is the most appropriate choice for the base rate.

\section{Exchange Rate Regime Coding}

The exchange rate regimes are classified both based on the legal commitment of countries to gold (the de jure status) as well as the de facto behavior of the exchange rate. De jure coding is based on the dates given by Obstfeld and Taylor (2003). The de jure status is in some sense a combination of the exchange rate regime and capital control regime sides of the trilemma as countries are considered to be off gold if they restricted convertibility in any way. The de facto standard follows the coding for the post-Bretton Woods era developed in Shambaugh (2004). We ask whether the monthly exchange rate stayed within \pm 2 percent bands over the course of a year. In addition, single realignments are not considered breaks in the regime as long as the transition is immediate from one peg to another. Finally, single-year pegs are dropped as they are quite likely a simple lack of volatility and it is unlikely that there exists either commitment on the government's part or confidence in the market that the rate will not change. ${ }^{15}$ We use the categories "peg" and "nonpeg" to classify currency regimes so as to emphasize that countries without pegged rates may not be "pure" floats in which exchange rate management is eschewed. Countries with nonpegs simply do not peg completely (according to our metric).

Because there is no single base country to which countries peg, exchange rates are tested for stability against gold by examining the exchange rate against the dollar during the dollar's peg to gold, and against the French franc in the two-year period (1933-34) of

\footnotetext{
${ }^{14}$ In addition, we tried both simply eliminating the base countries or including them using the United States as the base rate for France, Germany, and Britain.

${ }^{15}$ When pursuing differences regressions, we also drop the first year of a peg to avoid differencing interest rates across nonpegged and pegged observations. Shambaugh (2004) provides an extensive discussion of different de facto classifications. Recent work by Reinhart and Rogoff (2002), which uses data on parallel exchange rates, is not directly relevant to the present paper. Countries with parallel exchange markets employ capital controls to separate commercial from financial transactions, and for that reason alone are likely to enjoy some degree of monetary independence.
} 
dollar instability against gold. This provides a full series of codes for the countries that stayed pegged to gold on a de facto basis. ${ }^{16}$ Exchange rate data come from GFD.

\section{Capital Control Status}

To conduct our empirical analysis of the trilemma, we also need to code countries as to their use of capital controls. As mentioned, the de jure exchange rate regimes automatically incorporate this criterion. De facto capital control classifications have been created for more recent eras, but most are available only for a limited number of countries and a limited amount of time. Furthermore, some measures rely on interest differentials (the variable upon which we focus) and thus are not appropriate for the present study. No other clear source has been used to describe capital controls in this era before. We turn to two sources to generate our own coding of capital controls. The League of Nations publication Legislation on Gold (1930) gives a history of when countries returned to gold convertibility, so we are able to code at what point after World War One countries opened their capital markets to gold flows. In addition, the League of Nations' Monetary Review (1938) provides a table that describes when countries put in place exchange controls in the 1930s (Appendix Table 1, p. 107). Combining these sources gives us our measure of capital controls. Clearly, this binary measure is imperfect in capturing the range of effectiveness that various controls may have had, but we feel that it provides a useful indication of the countries trying to create breathing room by limiting cross-border financial flows.

\section{Individual Country Episodes}

For the dynamic time-series analysis based on specification (7), we study monthly data on individual country/regime episodes. Two types of episodes are examined. First we look at the de jure coding, which gives us thirteen pegged episodes and 21 nonpegged episodes (half of them occurring prior to the reconstituted gold standard, and half after). We also use our exchange rate regime coding methodology to generate a monthly classification of the currency regime in effect. We follow much the same method as for annual data, checking that the exchange rate has stayed within \pm 2 percent bands over the preceding twelve months. We then combine this information with our dates for capital controls to generate four types of episode: open pegs, closed pegs, open nonpegs, and closed nonpegs. Brief episodes of less than three years are excluded as too short to allow informative time-series inference. There are eleven open pegs, three closed pegs, four open nonpegs, and three closed nonpegs.

\section{Unit Roots in Interest Rates}

While the methodology section considers the fact that many time series of nominal interest rate data are difficult to distinguish from unit roots, this is not necessarily true for

\footnotetext{
${ }^{16}$ As an alternative, we also looked at the years the League of Nations listed a country as pegging to gold. The results are consistent with those reported below.
} 
the classical gold standard era. While showing persistence, the British interest rate, the clear base rate under the classical gold standard, is relatively stable as are the interest rates of most other gold standard countries. On the other hand, the interwar years appear to resemble the Bretton Woods or post-Bretton Woods eras, in that the interest rates of most countries show very strong serial correlation. Figures 1a, 1b, and 1c show the interest rates for the United States, France, and the combined gold interest rate. For comparison, Figure 1d shows Britain's interest rate during the classical gold standard.

Simple tests on monthly base and local interest rates back up this ocular evidence that interwar interest rates are highly persistent. The autocorrelation coefficient for the U.S. rate is 0.99 . The average autocorrelation coefficient for the other countries is 0.96 . More formally, we apply the unit root test suggested by Elliott, Rothenberg, and Stock (1996), using the modified Akaike Information Criterion of $\mathrm{Ng}$ and Perron (2001) to determine the appropriate number of lags to include. In addition, we test for stationarity using the KPSS test of Kwiatkowski, Phillips, Schmidt, and Shinn (1992), in which the null is stationarity rather than nonstationarity. For twelve countries, we cannot reject a unit root, but we can reject stationarity, implying that the interest rates are either nonstationary or very close. For three countries the data reject a unit root and cannot reject stationarity, while in one case the data can reject both, and in one case neither. As a general conclusion, the very high persistence in the data suggests that inference will be more reliable if they are treated as if they contain unit roots.

\section{Results}

\section{Results Based upon Pooled Differences}

We begin by presenting results for the differences equation (1), based on the de facto currency regime coding and using the gold interest rate as the base rate. Additional specifications show results for alternative classifications and alternative base interest rates.

The core empirical result of the paper is shown in Table 3, which reports estimates of equation (1). The results are obtained by OLS, using robust standard errors clustered at the country level. This procedure, along with the use of differenced data, removes problems of both serial correlation and heteroskedasticity that could be present in the panel. Also, because the data are in panel form, one may consider using fixed effects; but as the data are differenced, a constant fixed effect would imply an implausible constant rate of change over time. In any event, allowing for fixed effects has no impact on the estimates in practice, and the estimated fixed effects are always zero. ${ }^{17}$ Examining Table

${ }^{17}$ Observations for France are dropped for years in which its interest rate is a component of the base interest rate. Dropping France altogether has no substantial impact on the 
3, we see a difference between the way pegged countries and those that are not pegged react to the base interest rate. Countries, on average, move with the base interest rate to some degree: $\beta$ equals 0.30 . However, pegs shadow the base rate much more closely than nonpegs: $\beta$ for pegs is $0.57(0.13)$ versus $0.13(0.18)$ for nonpegs. These results are quite similar to the results for the classical gold standard, where the coefficient on pegs and nonpegs are, respectively, $0.52(0.04)$ and 0.05 (0.09) (see Table 4). The estimates also are quite close to the earlier simulation results for the $\rho\left(\Delta z, \Delta R_{b}\right)=0.8$ case (recall Table 1).

There is also a difference in the $R^{2}$ for pegs and nonpegs during the interwar years, as one would expect. The $R^{2}$ for the pegged sample of 0.16 versus 0.01 for the nonpegs. This difference matches the predictions of the trilemma, as the base country interest rate is a more important factor determining the local country interest rate for pegs than for nonpegs. Again, these differences in $R^{2}$ are quite close to those in the simulation results.

While the coefficients are somewhat close in the two gold standard eras, there is a clear difference in the explanatory power of the regressions. The difference in $R^{2}$ across pegs and nonpegs is far less striking than the classical gold standard (0.41 versus 0.00$)$, and is much closer to the results found in the post-Bretton Woods era (0.19 versus 0.01). This difference is likely in part a result of the increasing use of capital account restrictions in the interwar years, perhaps partly a result of the very large shocks hitting interwar economies, and also possibly a result of countries' taking more interest in using monetary policy for domestic stabilization.

The results are further bolstered by looking at the alternative definitions of the gold standard described earlier. The de jure classification, which essentially only codes countries as pegged if the currency is fully convertible, shows stronger results. These pegs are the countries operating under the full constraints of the trilemma, ones we would expect to have very little autonomy. Here, the $\beta$ coefficient for pegs is even larger than during the classical gold standard $[0.72(0.14)]$, and the $\beta$ coefficient for nonpegs is essentially zero $[0.07(0.18)]$. The $R^{2}$ on the pegged group also goes up to 0.33 , suggesting that during the relatively well-functioning portion of the interwar gold standard, gold adherence did operate as a strong constraint, nearly as strong as during the classical period.

We also separate out the two legs of the trilemma, exchange rate regimes, and capital controls, again using de facto exchange rate regimes, but now combined with our capital control measure. As expected, the group of observations that represents pegs with open capital markets shows the strongest connection to the base country (see Table 5). No other group generates a $\beta$ significantly different from zero or an $R^{2}$ even half the size of the open market pegs. The $R^{2}$ suggests that over 20 percent of the movement in local interest rates can be tied to the base rate. Thus, we see it is the combination of a fixed exchange

results. The United States is dropped in all years, as its rate is always a component of the base interest rate. 
rate and open capital markets that seems to generate the loss of autonomy. When countries either float or close their capital markets, they cease to follow the base as closely. ${ }^{18}$

Our interpretation is not without caveats, however. We cannot state clearly that the trilemma is forcing countries to follow the base because these results could be the consequence of pegged countries simply choosing to follow the base or experiencing shocks highly correlated with those hitting the base country. Previous work on the post-Bretton Woods era assumes a variety of base interest rates in a given time period, and thus allows the inclusion of time controls; distance and trade-share controls have been included as well. The currency regime and capital control regime variables still show strong impacts on the degree to which a country follows the base (Shambaugh, 2004).

Table 5 contains an apparent anomaly, though. The closed capital market nonpegs should be the group with the greatest monetary freedom. While all groups except open pegs should be able to pursue autonomous monetary policy to some degree, both conventional wisdom and results from other eras (see Obstfeld, Shambaugh, and Taylor, 2004) would suggest that the closed market nonpegs should be least linked to the base. There should be very little pressure on them to respond to the base interest rate, as they should have achieved substantial autonomy both through shutting capital markets and by not pegging. We find, though, that this group has a larger (though still statistically insignificant) estimated $\beta$ coefficient than do open nonpegs or closed pegs, and an $R^{2}$ of 0.07. This pattern indicates a stronger connection for this group than for the closed pegs or the open capital market nonpegs, and it is robust across a wide variety of base interest rate definitions and regime classifications. We return to this curious finding when we examine different time periods within the interwar sample.

We can further explore the results by pooling the data across regime and including an interaction term for pegging times the change in the base interest rate (see equation (2) above). The coefficient on peg times the change in the base rate is both large (0.43) and statistically significantly different from zero at the 95 percent level (see Table 6, column $1)$. The coefficient is even larger under the de jure coding $(0.62(0.22))$. This pooled estimation procedure allows us to show that the results across samples are statistically significant, though it removes the ability to test differences in the explanatory power of the regression across subsamples. The procedure also summarizes the results in a more compact manner, allowing us to display sensitivity across a variety of base interest rates.

18 The results on this point are even stronger than for other eras (see Obstfeld, Shambaugh, and Taylor, 2004). A similar table, pooling data across the gold standard, Bretton Woods and post-Bretton Woods eras, generates significant coefficients for both pegs with capital controls and nonpegs without, though in both cases the coefficients are smaller and the $R^{2}$ much lower than for open pegs. In those results, it seems that either closing capital markets or eliminating a peg restores some autonomy, but not as much as doing both. In the interwar years, either action seems to restore autonomy. 
Results using the U.S. interest rate instead of the gold interest rate are similar on the whole, but weaker. Results using the British interest rate are weaker still, with relatively low and insignificant coefficients on the sterling interest rate alone or when interacted with the peg dummy. Given the importance of France in the system and the fact that the United States broke from gold at one point, it is not surprising that the gold interest rate shows a stronger sway over pegged countries' interest rates than does the dollar rate alone. Likewise, given Britain's relatively brief tenure in the interwar gold standard, it is not surprising that the country does not appear to have provided a base interest rate for the system. The weak international connections to Britain's interest rate do, however, support the view that after World War I, London was no longer the unrivaled center of global financial power. This finding is therefore consistent with Kindleberger's (1986) argument that a shift in hegemonic financial power was in progress during the interwar years. The regressions breaking the base interest rate into different rates for different countries are reported in column 5 of Table 6 . It seems that either the U.S. rate alone or the U.S.-French rate in combination holds a much stronger sway over countries than the various bases that may have been regional or historical leaders. ${ }^{19}$ With each interest rate base, the divided sample results (analogous to those in Table 3) yield a significant coefficient on the peg sample and an insignificant one on the nonpeg sample. The coefficients on nonpegs are sometimes estimated so imprecisely, however, that the differences across groups are not statistically significant for every different base interest rate when the data are pooled.

Next, we may wonder whether the system behaved differently before and after its descent into crisis. We use 1931 as the watershed year, as it featured the departure of sterling from the system. We thus divide our sample into pre-1931 and post-1931. Table 7 shows that the pre-1931 results (the first three columns) look much like our results for the overall sample, reported in the first table. Pegs generate higher coefficients and higher $R^{2}$ than nonpegs and the predicted target zone coefficients in the neighborhood of 0.6 still arise. On the other hand, the post-1931 results are radically different. Both pegs and nonpegs show coefficients significantly different from zero and in fact greater than 1 , although we cannot reject that they are different from the frequently seen baseline estimate of 0.6. In addition, the source of the anomaly in Table 5, which we discussed earlier, comes to light. The closed capital market nonpegs show a coefficient significantly different from zero, indeed well above 1 , and an $R^{2}$ exceeding 0.2 . When splitting the data into such narrow groups, we arrive at a small number of observations (35 in the case of the closed nonpegs after 1931). Still, despite the small number of observations, this result is statistically significant at the 99 percent level.

${ }^{19}$ Using the U.S. rate for the first half of the sample and the bloc-based interest rates after Britain's 1931 departure from gold yields even weaker results than in column 5 of Table 6 . Thus, one cannot attribute the results to the fact that regionalization did not become pronounced until the system started to break down. 
As for the question of why closed nonpegs would follow the base so closely, one may hypothesize that the shock of the depression provoked similar responses in all countries, and thus all countries show a strong correlation with the gold interest rate. ${ }^{20}$ Alternatively, one might think that the chaos of the era left countries desperate to cling to any anchor they could find in order to restore stability. One strategy might have been to close off capital markets to avoid further attacks while following the base interest rate zealously in the hope of regenerating credibility. As it turns out, this latter explanation seems to have some plausibility, as all the countries that are closed market nonpegs repeg relatively quickly. Ten countries produce observations in this group, and all of them repeg before the end of the sample. Thus, at least for some countries, the 1930 s seem not so much an era of pure monetary nationalism, as a time of desperate attempts to repeg. Table 8 shows the countries in this group and the years they are considered closed nonpegs. None stays nonpegged straight through to 1938; all restore a peg at some point. Many - for example, Czechoslovakia-appear to be freer than they were in reality, as they peg briefly during some of the years they are listed as nonpegs, but not consistently enough to be considered a peg in those years. We return to these questions in the levels analysis.

\section{Time-Series Levels Analysis}

We can explore these issues further by examining individual country relationships with the base interest rate. To do so we use the PSS methodology to test for the existence of levels relationships between interest rates, simultaneously examining the dynamics of adjustment.

Table 9 shows the individual results grouped by type of episode. The de jure results have the advantage of only having to group countries by one measure. We examine three groups, pegs, nonpegs before 1931, and nonpegs starting in 1931. It appears that the relationship seen at the pooled panel level still holds at the individual level. By and large, the pegs seem to follow the base rate (Table 9a shows the gold interest rate results). Six out of the thirteen episodes are significant at both the $I(1)$ and $I(0)$ critical values, the average cointegrating coefficient is 0.53 and the average half-life of adjustment is five months. In addition, only one episode (Germany) has a backwards level relationship (that is, $\gamma<0$ ) and only one other (Italy) has a half-life of over twelve months. Nine out of the thirteen have a levels relationship of the correct sign and half lives below six months.

Nonpegs do not show such a close relationship. Of the pre-1931 nonpegs, only one has a levels relationship that is both significant and in the correct direction. The average coefficient is -0.01 , and the average adjustment half-life is 29 months. Also, two of the

${ }^{20}$ Results on individual countries, presented next, show that not all countries moved together. That finding suggests that not all the results are due simply to common shocks. The results are not driven strictly by the choice of a base country. Results for pre- and post-1931 look broadly similar for the U.S. interest rate as a base. Using the British interest rate as a base, though, shows very weak results, with pegs generating a coefficient of $0.25(0.11)$ versus $0.27(0.16)$ for nonpegs. 
eight cases have backwards levels relationships and three more have adjustment half-lives in excess of twelve months. Only China and the United Kingdom show much of a connection to the base rate. Post-1930 nonpegs show almost no connection at all with the gold interest rate. While two of the eleven have significant levels relationships in the expected direction, eight of the eleven have levels relationships that imply they move against the base country interest rate. ${ }^{21}$

While the pre-1931 and peg results are broadly the same if one uses the U.S. interest rate instead of the gold interest rate, the post-1930 nonpeg results look quite different based on the U.S. interest rate. ${ }^{22}$ Three of the eleven have a significant levels relationship in the expected direction and another four have insignificant relationships in the expected direction, with adjustment half-lives below seven months, leaving only four rates that run opposite to the U.S. rate. This pattern suggests that by the end of the era, when the gold standard had largely fallen apart, France's role as a center country had diminished. As discussed above, we are not surprised to see some of the de jure nonpegs follow the United States from 1931 on. Many of these countries are in the process of reestablishing their exchange rate pegs or at the very least are in desperate straits, struggling for some credibility. On the other hand, some countries clearly are not following the United States, so it seems that common global shocks are not the sole factor behind the strong post-1931 relationships seen in the pooled data. Britain, China, India, and Romania all have negative relationships with the United States in their nonpegs of the 1930s.

When we classify the episodes by both exchange rate regime and capital control status, we have eleven open pegs, four open nonpegs, three closed pegs, and three closed nonpegs. Thus, there are too few country episodes to speak meaningfully about averages across groups, but we do see some suggestive patterns. By and large, the open pegs show a fairly strong connection with the gold interest rate. Three of the eleven show statistically significant positive relationships with an overall average of 0.67 and an adjustment halflife of seven months. No episodes show a negative levels relationship and only two have adjustment half-lives above twelve months. Once again, it appears that the countries we expect to be constrained by the trilemma show evidence of that constraint.

Alternatively, in the episodes of closed nonpegs, countries do not appear to follow the Unites States. Two of the three show negative levels relationships. Only Britain prior to

${ }^{21}$ The average adjustment speeds match our simulations as well, with mean $\theta$ equal to roughly -0.2 for pegs and -0.1 for nonpegs. However, the average $\theta$ for post-1931 nonpegs is not very informative regarding autonomy because in most cases, countries are adjusting interest rates away from the base.

${ }^{22}$ The results for the pegs are slightly weaker when using the U.S. rate, dropping the levels relationship to roughly 0.36 with an adjustment half-life of roughly five months. The pre-1931 nonpegs are as unconnected to the U.S. rate alone as to the gold interest rate, with a negative average levels relationship, an average adjustment half-life of over 28 months, three out of eight with negative levels relationships, two more slower than twelve months, and only one significant positive relationship. 
its return to gold shows a strong connection at all, with an insignificant (but close to unity) levels relationship and an adjustment half-life below six months. Britain in the years 1921-24 was intent on returning to gold and, thus, was following the United States quite closely; it was not trying to pursue an independent course, but it lacked credibility and reserves sufficient to rejoin the gold standard. The pre-1925 British result supports our contention that closed nonpegs in the post-1931 era show strong comovements with the base rate because they were hoping to repeg. Interestingly, there are no closed nonpegged episodes from the post-1931 era because no country in our sample maintained a nonpeg and closed capital markets for as long as three years (our criterion for consideration as a distinct "episode"). Countries either briefly returned to pegs to break up strings of nonpegging, or repegged within three years of leaving gold.

The results for the closed pegs are fairly close to those for open pegs, suggesting that perhaps closing capital markets does not entirely insulate a country if it intends to maintain a peg for a considerable length of time. None of the three levels relationships is significant, but they are all positive, and two are quite close to 1 . The adjustment halflives are all estimated to be between four and eight months. Our data comprise only three examples, though, of countries that maintained closed pegs for any extended period, so it is difficult to conclude much about them. The open nonpegs are split, with two (Britain, 1931-34 and Italy, 1922-27) showing insignificant negative levels relationships; one (Sweden, 1931-34) showing an insignificant, slowly adjusting, positive relationship; and one, (India, 1931-34) showing a significant positive relationship with an adjustment halflife of one month. ${ }^{23}$

A final point worth noting is that interest rates in France and the United States were never that closely related. Both during France's prepegging episode from 1922 to 1926, and during its peg from 1928 to 1936, a negative levels relationship prevailed. Thus, one sees part of the great tension in the system as a whole during this era: the two center countries with the bulk of the gold reserves were moving their interest rates independently, making it difficult for countries to follow a single base.

\section{Summary}

The two types of econometric analysis broadly support the predictions of the trilemma. The pooled analysis shows that short-run interest rate movements in the pegged countries, especially when they have open capital markets, follow the base interest rate. The levels analysis shows that on average, it is the open pegs or de jure pegs that follow the base the

${ }^{23}$ The patterns when the U.S. interest rate is the base are similar, with the open pegs showing similar results episode by episode, though with a slightly lower average half-life (in particular, Austria, Hungary, and India are somewhat weaker against the U.S. interest rate than against the gold interest rate). In other groups, Germany shows a weaker relationship to the dollar rate as compared with the gold interest rate. Sweden's interest rate during its open nonpeg has a significant levels relationship with the dollar rate despite its insignificant relationship with the gold interest rate. 
most closely over time. Notably, many nonpegs seem to show considerable independence from the base interest rate at many points in the sample. A number of countries that are briefly floating do combine to generate a high average response of closed nonpegs to the base rate during the Great Depression, but this is largely an anomaly in our sample and the result is not significant.

Thus, we see that "fear of floating" type of behavior, while present in some cases, was not at all universal in our sample period as a whole. Many nonpeg countries were able to move their interest rates in ways quite distinct from the base country. On the other hand, in times of crisis, more floating rate countries may have chosen to follow the base in an attempt to repeg, may have been forced to follow the base or risk further speculative attack, or may simply have been following the base because of globally synchronized responses to large common shocks.

The trilemma finds considerable empirical support in this era, and the empirics generate results that are numerically consistent with theoretical, model-based simulations. The trilemma was a constraint on policy for countries that fixed their exchange rate and maintained open capital markets. They lost much of their monetary autonomy compared with countries that adopted alternative regimes. The results also show why the architects of Bretton Woods were so concerned to create a system that would allow for some monetary autonomy notwithstanding stable exchange rates. The fact that some floaters did not pursue autonomy (as they could have), and instead managed interest rates with an eye toward returning to a peg, may have convinced contemporaries like Keynes and Nurkse that the potential instability of floating rates was not effectively compensated by any meaningful policy freedom. That view, in turn, led to the Bretton Woods consensus in favor of fixed exchange rates coupled with capital account control.

\section{Conclusion}

Up until now, the empirical content of the trilemma and, hence, its practical relevance, have remained largely untested. Our work seeks to show that the trilemma is a central feature of the macroeconomic world we have lived in for a century or more. Understood in a target-zone context, the real world content of the trilemma does deviate from the simplistic idea of full international interest rate equalization, but only in degree. It is true that this deviation confers a little independence on policymakers even under hard gold standard rules (Bordo, 2003; Bordo and Flandreau, 2003; and Bordo and MacDonald, 1997, 2003). But that independence is very limited indeed, we would argue. Under open capital markets and pegged exchange rates, the half lives of interest rate deviations can be counted in months, and interest rate pass-through is very strong whether before or after World War I, or even today. It is not clear that such meager room for maneuver can offer any significant scope for purposeful macroeconomic management, especially when compared to the far slower adjustment and lower pass-through seen in floating or closed 
capital-market countries. Only a move to floating or the imposition of capital controls can free monetary policy to pursue domestic aims, and in practice they seem to do so.

Spanning, as it does, a century or more of experience, our empirical work in this and other papers highlights the enduring power of this principle. In this sense, we would argue that the trilemma is alive and well. As a working proposition, it merits attention from a wide audience, if our work is found to be persuasive. As a narrative hook, historians and political scientists have often invoked or criticized its applicability, but with little empirical evidence to guide interpretation. International economists will find an old familiar part of their toolkit now has been sharpened up by use in the field. Last, but not least, policymakers may better comprehend the true nature of the constraints under which they must operate in an open economy.

\section{REFERENCES}

Baxter, Marianne, and Alan C. Stockman, 1989, "Business Cycles and the Exchange rate Regime: Some International Evidence," Journal of Monetary Economics 23 (May), pp. 377-400.

Bloomfield, Arthur I., 1959, Monetary Policy Under the International Gold Standard: 1880-1914, (New York: Federal Reserve Bank of New York).

Board of Governors of the Federal Reserve System, 1943, Banking and Monetary Statistics 1914-1941, (Washington: Board of Governors of the Federal Reserve System).

Bordo, Michael D., 2003, "Exchange Rate Regime Choice in Historical Perspective," NBER Working Paper 9654 (Cambridge, Massachusetts: National Bureau of Economic Research).

- - - and Marc Flandreau, 2003, "Core, Periphery, Exchange Rate Regimes, and Globalization," in Globalization in Historical Perspective, edited by M.D. Bordo, A.M. Taylor, and J.G. Williamson (Chicago: University of Chicago Press).

Bordo, Michael D., and Ronald MacDonald, 1997, "Violations of the 'Rules of the Game' and the Credibility of the Classical Gold Standard, 1880-1914," NBER Working Paper 6115 (Cambridge, Massachusetts: National Bureau of Economic Research).

- - - 2003, "The Inter-War Gold Exchange Standard: Credibility and Monetary Independence," Journal of International Money and Finance, Vol. 22, No. 1, pp. $1-33$.

Eichengreen, Barry J., 1996, Globalizing Capital: A History of the International Monetary System (Princeton: Princeton University Press).

- - - and Douglas A. Irwin, 1995, "Trade Blocs, Currency Blocs, and the Reorientation of World Trade in the 1930s," Journal of International Economics, Vol. 38 (February), pp. 1-24. 
Elliott, Graham, Thomas J. Rothenberg, and James H. Stock, 1996, "Efficient Tests for an Autoregressive Unit Root,” Econometrica, Vol. 64 (July), pp. 813-36.

Flood, Robert P., and Peter M. Garber, 1991, "The Linkage Between Speculative Attacks and Target Zone Models of Exchange Rates," Quarterly Journal of Economics, Vol. 106 (November), pp. 1367-72.

Flood, Robert P., and Andrew K. Rose, 1995, "Fixing Exchange Rates: A Virtual Quest for Fundamentals," Journal of Monetary Economics, Vol. 36 (August), pp. 3-37.

Froot, Kenneth A., and Maurice Obstfeld, 1991, "Stochastic Process Switching: Some Simple Solutions," Econometrica, Vol. 59 (January), pp. 241-50.

Frankel, Jeffrey A., Sergio L. Schmukler, and Luis Servén, 2002, "Global Transmission of Interest Rates: Monetary Independence and Currency Regime," NBER Working Paper 8828 (Cambridge, Massachusetts: National Bureau of Economic Research).

Goschen, George J., 1861, The Theory of the Foreign Exchanges (London: Effingham Wilson).

James, Harold, 2001, The End of Globalization: Lessons from the Great Depression (Cambridge, Massachusetts: Harvard University Press).

Kindleberger, Charles P., 1986, The World in Depression, 1929-1939, revised and enlarged edition (Berkeley and Los Angeles: University of California Press).

Krugman, Paul R., 1991, "Target Zones and Exchange Rate Dynamics," Quarterly Journal of Economics, Vol. 106 (August), pp. 669-82.

Kwiatkowski, Dennis, Peter Phillips, Peter Schmidt, and Yongcheol Shinn, 1992, "Testing the Null Hypothesis of Stationarity Against the Alternative of a Unit Root: How Sure Are We That Economic Time Series Have a Unit Root?” Journal of Econometrics, Vol. 54, pp. 159-78.

League of Nations, 1930, Legislation on Gold (Geneva: League of Nations).

- _ - 1938, Monetary Review 1937/8 (Geneva: League of Nations).

- - - Statistical Yearbooks, various editions.

Lindsey, Brink, 2002, Against the Dead Hand: The Uncertain Struggle for Global Capitalism (New York: John Wiley \& Sons).

Mouré, Kenneth, 2002, The Gold Standard Illusion: France, the Bank of France, and the International Gold Standard, 1914-39 (Oxford: Oxford University Press).

Neal, Larry, and Marc Weidenmier, 2003, "Crises in the Global Economy from Tulips to Today: Contagion and Consequences," in Globalization in Historical Perspective, edited by M.D. Bordo, A.M. Taylor, and J.G. Williamson (Chicago: University of Chicago Press).

Ng, Serena, and Pierre Perron, 2001, "Lag Length Selection and the Construction of Unit Root Tests with Good Size and Power," Econometrica, Vol. 69 (November), pp. 1519-54.

Obstfeld, Maurice, Jay C. Shambaugh, and Alan M. Taylor, 2004, “The Trilemma in History: Tradeoffs Among Exchange Rates, Monetary Policies, and Capital 
Mobility" NBER Working Paper 10396 (Cambridge, Massachusetts: National Bureau of Economic Research).

Obstfeld, Maurice, and Alan M. Taylor, 1998, “The Great Depression As a Watershed: International Capital Mobility over the Long Run," in The Defining Moment: The Great Depression and the American Economy in the Twentieth Century, edited by M.D. Bordo, C.D. Goldin, and E.N. White (Chicago: University of Chicago Press).

Obstfeld, Maurice, and Alan M. Taylor, 2003, "Sovereign Risk, Credibility, and the Gold Standard: 1870-1913 versus 1925-31," Economic Journal, Vol. 113 (April), pp. $1-35$.

- - , 2004, Global Capital Markets: Integration, Crisis, and Growth (Cambridge, England: Cambridge University Press).

Pesaran, M. Hashem, Yongcheol Shin, and Richard J. Smith, 2001, "Bounds Testing Approaches to the Analysis of Level Relationships," Journal of Applied Econometrics, Vol. 16 (May/June), pp. 289-326.

Polanyi, Karl, 1944, The Great Transformation (New York: Rinehart).

Reinhart, Carmen M., and Kenneth S. Rogoff, 2004, "The Modern History of Exchange Rate Arrangements: A Reinterpretation," Quarterly Journal of Economics, Vol. 119, No. 1, pp. 1-48.

Romer, David, 2001, Advanced Macroeconomics, second edition (New York: McGrawHill).

Rose, Andrew K., 1996, “Explaining Exchange Rate Volatility: An Empirical Analysis of 'The Holy Trinity' of Monetary Independence, Fixed Exchange Rates, and Capital Mobility," Journal of International Money and Finance, Vol. 15, No. 6, pp. 925-45.

Scammell, W.M., 1965, "The Working of the Gold Standard," Yorkshire Bulletin of Economic and Social Research, Vol. 12, pp. 32-45.

Shambaugh, Jay C., 2004, "The Effects of Fixed Exchange Rates on Monetary Policy," Quarterly Journal of Economics, Vol. 119, No. 1, pp. 301-52.

Svensson, Lars E.O., 1991, "The Term Structure of Interest Rate Differentials in a Target Zone: Theory and Swedish Data," Journal of Monetary Economics, Vol. 28 (August), pp. 87-116.

Temin, Peter, 1989, Lessons from the Great Depression (Cambridge, Massachusetts: MIT Press).

Tortella, Gabriel, 2003, "Democracy and Gold" (unpublished; Universidad de Alcalá).

Yergin, Daniel, and Joseph Stanislaw, 1998, The Commanding Heights: The Battle Between Government and the Marketplace that Is Remaking the Modern World (New York: Simon \& Schuster). 
Table 1 Simulated Estimates of $\beta$ and $\theta$ (Three-Month Interest Rates)

\begin{tabular}{|c|c|c|c|c|c|}
\hline Regime & $\hat{\beta}_{\text {DIFFS }}$ & $R_{\text {DIFFS }}^{2}$ & $\hat{\beta}_{\text {LEVELS }}$ & $R_{\text {LEVELS }}^{2}$ & $\hat{\theta}$ \\
\hline \multicolumn{6}{|l|}{$\rho\left(\Delta z, \Delta R_{b}\right)=0.8$} \\
\hline Target Zone $( \pm 1 \%)$ & $\begin{array}{c}0.50 \\
(0.07)\end{array}$ & 0.13 & $\begin{array}{c}0.83 \\
(0.12)\end{array}$ & 0.83 & $\begin{array}{r}-0.22 \\
(0.07)\end{array}$ \\
\hline Float & $\begin{array}{c}0.16 \\
(0.07)\end{array}$ & 0.02 & $\begin{array}{c}0.61 \\
(0.22)\end{array}$ & 0.52 & $\begin{array}{r}-0.10 \\
(0.05)\end{array}$ \\
\hline \multicolumn{6}{|l|}{$\rho\left(\Delta z, \Delta R_{b}\right)=0.5$} \\
\hline Target Zone $( \pm 1 \%)$ & $\begin{array}{c}0.69 \\
(0.08)\end{array}$ & 0.20 & $\begin{array}{c}0.89 \\
(0.12)\end{array}$ & 0.84 & $\begin{array}{l}-0.21 \\
(0.06)\end{array}$ \\
\hline Float & $\begin{array}{c}0.46 \\
(0.08)\end{array}$ & 0.05 & $\begin{array}{c}0.76 \\
(0.26)\end{array}$ & 0.49 & $\begin{array}{l}-0.09 \\
(0.04)\end{array}$ \\
\hline \multicolumn{6}{|l|}{$\rho\left(\Delta z, \Delta R_{b}\right)=0$} \\
\hline Target Zone $( \pm 1 \%)$ & $\begin{array}{c}0.99 \\
(0.08)\end{array}$ & 0.33 & $\begin{array}{c}1.00 \\
(0.13)\end{array}$ & 0.86 & $\begin{array}{l}-0.20 \\
(0.06)\end{array}$ \\
\hline Float & $\begin{array}{c}0.97 \\
(0.10)\end{array}$ & 0.27 & $\begin{array}{c}0.98 \\
(0.26)\end{array}$ & 0.67 & $\begin{array}{r}-0.09 \\
(0.04)\end{array}$ \\
\hline \multicolumn{6}{|l|}{$\rho\left(\Delta z, \Delta R_{b}\right)=-0.5$} \\
\hline Target Zone $( \pm 1 \%)$ & $\begin{array}{c}1.28 \\
(0.10)\end{array}$ & 0.43 & $\begin{array}{c}1.10 \\
(0.13)\end{array}$ & 0.86 & $\begin{array}{l}-0.20 \\
(0.06)\end{array}$ \\
\hline Float & $\begin{array}{c}1.44 \\
(0.17)\end{array}$ & 0.47 & $\begin{array}{c}1.19 \\
(0.25) \\
\end{array}$ & 0.77 & $\begin{array}{r}-0.10 \\
(0.04) \\
\end{array}$ \\
\hline
\end{tabular}


Table 2

\begin{tabular}{llrr} 
& Frequency & Dates available \\
\hline Austria & monthly & $1 / 1923$ & $6 / 1931$ \\
Belgium & monthly & $5 / 1919$ & $12 / 1938$ \\
Bulgaria & monthly & $1 / 1928$ & $12 / 1938$ \\
Chile & annual & 1929 & 1936 \\
China & monthly & $1 / 1928$ & $12 / 1938$ \\
Czechoslovakia & monthly & $1 / 1926$ & $12 / 1938$ \\
Denmark & annual & 1926 & 1938 \\
France & monthly & $1 / 1922$ & $12 / 1938$ \\
Germany & monthly & $1 / 1919$ & $12 / 1938$ \\
Hungary & monthly & $7 / 1924$ & $12 / 1938$ \\
India & monthly & $4 / 1921$ & $12 / 1938$ \\
Italy & monthly & $1 / 1922$ & $12 / 1938$ \\
Japan & monthly & $1 / 1919$ & $12 / 1938$ \\
Netherlands & monthly & $1 / 1919$ & $12 / 1938$ \\
Romania & monthly & $1 / 1929$ & $12 / 1938$ \\
Sweden & monthly & $1 / 1926$ & $12 / 1938$ \\
Switzerland & monthly & $1 / 1924$ & $12 / 1938$ \\
United Kingdom & monthly & $1 / 1919$ & $12 / 1938$ \\
United States & monthly & $1 / 1919$ & $12 / 1938$ \\
\hline
\end{tabular}


Table 3 Core results (uses gold interest rate as the base interest rate)

dependent variable: $\Delta R_{\text {it }}$

\begin{tabular}{lccccc} 
& 1 & 2 & 3 & 4 & 5 \\
& full & df pegs & $\begin{array}{c}3 \\
\text { df nonpegs }\end{array}$ & $\begin{array}{c}\text { dj pegs } \\
\text { dj nonpegs }\end{array}$ \\
\hline$\beta(\Delta$ goldR $)$ & 0.300 & 0.567 & 0.128 & 0.720 & 0.072 \\
std error & $(0.116)^{*}$ & $(0.134)^{* *}$ & $(0.178)$ & $(0.144)^{* *}$ & $(0.185)$ \\
& & & & & \\
Observations & 240 & 109 & 106 & 66 & 163 \\
R-squared & 0.04 & 0.16 & 0.01 & 0.33 & 0.00 \\
\hline
\end{tabular}

Notes:

$\mathrm{df}=$ de facto classification, $\mathrm{dj}=$ de jure classification

Robust standard errors in parentheses

* significant at $5 \%$; * significant at $1 \%$ 
dependent variable: $\Delta R_{\mathrm{it}}$

\begin{tabular}{lcccc} 
& $\begin{array}{c}\text { Gold Standard } \\
\text { pegs }\end{array}$ & $\begin{array}{c}\text { Gold Standard } \\
\text { nonpegs }\end{array}$ & $\begin{array}{c}\text { Post BW } \\
\text { pegs }\end{array}$ & $\begin{array}{c}\text { Post BW } \\
\text { nonpegs }\end{array}$ \\
\hline$\beta(\Delta$ baseRit $)$ & 0.52 & 0.05 & 0.46 & 0.27 \\
std error & $(0.04)^{* *}$ & $(0.09)$ & $(0.04)^{* *}$ & $(0.08)^{* *}$ \\
& & & & \\
Observations & 399 & 85 & 748 & 1103 \\
R-squared & 0.41 & 0.00 & 0.19 & 0.01 \\
\hline
\end{tabular}

Notes:

Robust standard errors in parentheses

$*$ significant at $5 \%$;* significant at $1 \%$ 
Table 5 Splitting sample by exchange rate regime and capital controls using de facto coding

dependent variable: $\Delta \mathrm{R}_{\text {it }}$

\begin{tabular}{lcccc} 
& 1 & 2 & 3 & 4 \\
& peg open & peg closed & nonpeg open & nonpeg closed \\
\hline$\beta(\Delta$ goldRit $)$ & 0.647 & 0.183 & -0.315 & 0.307 \\
std error & $(0.153)^{* *}$ & $(0.349)$ & $(0.277)$ & $(0.210)$ \\
& & & & \\
Observations & 79 & 30 & 40 & 66 \\
R-squared & 0.21 & 0.02 & 0.03 & 0.07 \\
\hline
\end{tabular}

Notes:

Robust standard errors in parentheses

* significant at 5\%; ** significant at $1 \%$ 
dependent variable: $\Delta \mathrm{R}_{\text {it }}$

\begin{tabular}{lccccc} 
& $\begin{array}{c}1 \\
\text { de facto } \\
\text { Gold R }\end{array}$ & $\begin{array}{c}2 \\
\text { de jure } \\
\text { Gold R }\end{array}$ & $\begin{array}{c}3 \\
\text { de facto } \\
\text { US R }\end{array}$ & $\begin{array}{c}4 \\
\text { de facto } \\
\text { UK R }\end{array}$ & 5 \\
\hline$\beta_{1}(\Delta$ goldRit $)$ & 0.134 & 0.076 & 0.206 & 0.098 & 0.129 \\
std error & $(0.177)$ & $(0.185)$ & $(0.148)$ & $(0.145)$ & $(0.134)$ \\
$\beta_{2}$ (peg x $\Delta$ goldR it $)$ & 0.425 & 0.62 & 0.217 & 0.18 & 0.219 \\
std error & $(0.174)^{*}$ & $(0.217)^{*}$ & $(0.135)$ & $(0.178)$ & $(0.144)$ \\
& & & & & \\
Observations & 215 & 229 & 224 & 207 & 219 \\
R-squared & 0.08 & 0.10 & 0.09 & 0.06 & 0.09 \\
& & & & & \\
$\beta_{1}+\beta_{2}$ & 0.559 & 0.696 & 0.423 & 0.278 & 0.348 \\
\hline
\end{tabular}

Notes:

Robust standard errors in parentheses

$*$ significant at $5 \% ; * *$ significant at $1 \%$

$\mathrm{DF}=$ de facto coding, $\mathrm{DJ}=$ de jure coding, bloc $=$ different bases using currency bloc coding 
Table 7 Examining pre and post 1931 (uses de facto coding and gold interest rate as base)

dependent variable: $\Delta \mathrm{R}_{\mathrm{it}}$

\begin{tabular}{lccccccc} 
& $\begin{array}{c}\text { pre-31 } \\
\text { full }\end{array}$ & $\begin{array}{c}\text { pre-31 } \\
\text { pegs }\end{array}$ & $\begin{array}{c}\text { pre-31 } \\
\text { nonpegs }\end{array}$ & $\begin{array}{c}\text { post-31 } \\
\text { full }\end{array}$ & $\begin{array}{c}\text { post-31 } \\
\text { pegs }\end{array}$ & $\begin{array}{c}\text { post-31 } \\
\text { nonpegs }\end{array}$ & $\begin{array}{c}\text { post-31 } \\
\text { nonpeg clsd }\end{array}$ \\
\hline$\beta(\Delta$ goldRit $)$ & 0.292 & 0.576 & 0.122 & 1.146 & 1.218 & 1.304 & 1.353 \\
std error & $(0.147)$ & $(0.144)^{* *}$ & $(0.220)$ & $(0.206)^{* *}$ & $(0.483)^{*}$ & $(0.359)^{* *}$ & $(0.341)^{* *}$ \\
& & & & & & & \\
Observations & 111 & 56 & 46 & 112 & 42 & 54 & 35 \\
R-squared & 0.05 & 0.21 & 0.01 & 0.14 & 0.15 & 0.19 & 0.23 \\
\hline
\end{tabular}

Notes:

Robust standard errors in parentheses

* significant at 5\%; ** significant at $1 \%$ 
Table 8 Observations that are closed nonpegs post 1931

\begin{tabular}{ll} 
Country & Years \\
\hline Bulgaria & $1933-6$ \\
China & $1934-5,1938$ \\
Czechoslovakia & $1933-6$ \\
Germany & 1933 \\
Hungary & 1933,1936 \\
Italy & $1934-6$ \\
Japan & $1932-5,1938$ \\
Romania & $1933-6$ \\
Chile & $1932-6$ \\
Denmark & $1932-4,1938$ \\
\hline
\end{tabular}




\section{Table 9. PSS Results}

\section{Table 9a. De Jure Pegs to Gold Interest Rate}

\begin{tabular}{|c|c|c|c|c|c|c|c|c|c|c|c|}
\hline & lag chosen & $\theta$ & $\gamma$ & tstat $\theta$ & sig at 0 & sig at 1 & half-life & $<3$ & 3 to 12 & $>12$ & \#obs \\
\hline austria $3 / 25-9 / 31$ & 1 & -0.10 & 0.31 & -3.47 & 1 & 1 & 6.31 & 0 & 1 & 0 & 76 \\
\hline belgium $10 / 26-2 / 35$ & 1 & -0.23 & 0.61 & -5.14 & 1 & 1 & 2.71 & 1 & 0 & 0 & 101 \\
\hline bulgaria 4/28 - 12/31 & 0 & -0.12 & 0.60 & -1.64 & 0 & 0 & 5.37 & 0 & 1 & 0 & 44 \\
\hline czechoslovakia 1/29 - 12/31 & 5 & -0.72 & 0.40 & -2.81 & 0 & 0 & 0.54 & 1 & 0 & 0 & 36 \\
\hline germany $10 / 24-6 / 31$ & 3 & -0.18 & -0.75 & -4.48 & 1 & 1 & 3.51 & 0 & 1 & 0 & 81 \\
\hline hungary $4 / 25-7 / 31$ & 0 & -0.12 & 0.43 & -4.10 & 1 & 1 & 5.47 & 0 & 1 & 0 & 76 \\
\hline india $3 / 27-8 / 31$ & 1 & -0.30 & 0.72 & -3.76 & 1 & 1 & 1.97 & 1 & 0 & 0 & 54 \\
\hline italy $2 / 28-11 / 34$ & 1 & -0.05 & 1.18 & -1.76 & 0 & 0 & 13.24 & 0 & 0 & 1 & 83 \\
\hline netherlands $4 / 25-8 / 36$ & 2 & -0.23 & 1.03 & -3.39 & 1 & 1 & 2.69 & 1 & 0 & 0 & 137 \\
\hline romania $1 / 29-12 / 32$ & 0 & -0.16 & 0.98 & -2.08 & 0 & 0 & 3.98 & 0 & 1 & 0 & 44 \\
\hline sweden $3 / 24-8 / 31$ & 0 & -0.26 & 0.53 & -2.72 & 0 & 0 & 2.32 & 1 & 0 & 0 & 67 \\
\hline switzerland $1 / 25-12 / 36$ & 1 & -0.06 & 0.52 & -2.31 & 0 & 0 & 11.20 & 0 & 1 & 0 & 144 \\
\hline UK 4/25 - 8/31 & 0 & -0.15 & 0.40 & -1.81 & 0 & 0 & 4.36 & 0 & 1 & 0 & 77 \\
\hline averages & & -0.21 & 0.53 & -3.03 & 0.46 & 0.46 & 4.90 & 0.38 & 0.54 & 0.08 & 78.46 \\
\hline
\end{tabular}

\footnotetext{
Notes:

lag

$\gamma$

tstat $\theta$

sig at 0

sig at 1

half-life

\#obs

lag chosen based on Akaike information criteria

the adjustment speed to shocks in the levels relationship

the levels relationship

the t-stat on the adjustment speed which is used to determine the signficiance of the levels relationship

signifies whether we can reject no levels relationship if we assume stationary data

signifies whether we can reject no levels relationship if we assume non-stationary data

the half-life of the shock based on the adjustment speed

number of observations for the episode
} 
Table 9b. De Jure Pre 1931 nonpegs

\begin{tabular}{|c|c|c|c|c|c|c|c|c|c|c|c|}
\hline & lag chosen & $\theta$ & $\gamma$ & tstat $\theta$ & sig at 0 & sig at 1 & half-life & $<3$ & 3 to 12 & $>12$ & \#obs \\
\hline belgium pre- $10 / 26$ & 0 & -0.02 & 0.17 & -0.68 & 0 & 0 & 29.79 & 0 & 0 & 1 & 88 \\
\hline china pre 31 & 0 & -0.16 & 0.79 & -1.20 & 0 & 0 & 3.95 & 0 & 1 & 0 & 35 \\
\hline india up to $2 / 27$ & 1 & -0.24 & -0.54 & -3.86 & 1 & 1 & 2.49 & 1 & 0 & 0 & 69 \\
\hline italy up to $1 / 28$ & 1 & -0.03 & -1.78 & -1.50 & 0 & 0 & 25.32 & 0 & 0 & 1 & 70 \\
\hline japan up to $12 / 29$ & 0 & -0.01 & 0.20 & -0.28 & 0 & 0 & 138.28 & 0 & 0 & 1 & 131 \\
\hline netherlands up to $3 / 25$ & 1 & -0.41 & 0.13 & -5.05 & 1 & 1 & 1.32 & 1 & 0 & 0 & 73 \\
\hline switzerland up to $12 / 24$ & 0 & -0.03 & 0.29 & -2.07 & 0 & 0 & 22.01 & 0 & 0 & 1 & 71 \\
\hline UK up to $3 / 25$ & 0 & -0.08 & 0.58 & -1.33 & 0 & 0 & 8.77 & 0 & 1 & 0 & 74 \\
\hline averages & & -0.12 & -0.02 & -2.00 & 0.25 & 0.25 & 28.99 & 0.25 & 0.25 & 0.50 & 76.38 \\
\hline
\end{tabular}

\footnotetext{
Notes:

lag

$\theta$

lag chosen based on Akaike information criteria

$\gamma$

the adjustment speed to shocks in the levels relationship

the levels relationship

sig at 0

sig at 1

half-life

the t-stat on the adjustment speed which is used to determine the signficiance of the levels relationship

signifies whether we can reject no levels relationship if we assume stationary data

signifies whether we can reject no levels relationship if we assume non-stationary data

the half-life of the shock based on the adjustment speed

\#obs

number of observations for the episode
} 
Table 9c. De Jure Post 1930 Nonpegs

\begin{tabular}{|c|c|c|c|c|c|c|c|c|c|c|c|}
\hline & lag chosen & $\theta$ & $\gamma$ & tstat $\theta$ & sig at 0 & sig at 1 & half-life & $<3$ & 3 to 12 & $>12$ & \#obs \\
\hline bulgaria post $12 / 31$ & 0 & -0.03 & 0.53 & -2.14 & 0 & 0 & 22.76 & 0 & 0 & 1 & 84 \\
\hline china post $12 / 30$ & 0 & -0.16 & -0.14 & -2.77 & 0 & 0 & 4.03 & 0 & 1 & 0 & 96 \\
\hline czechoslovakia post $12 / 31$ & 8 & -0.08 & -0.25 & -3.50 & 1 & 1 & 8.65 & 0 & 1 & 0 & 84 \\
\hline germany post $6 / 31$ & 1 & -0.07 & -2.45 & -1.59 & 0 & 0 & 9.14 & 0 & 1 & 0 & 90 \\
\hline hungary post $7 / 31$ & 6 & -0.08 & -0.27 & -2.93 & 1 & 0 & 8.42 & 0 & 1 & 0 & 89 \\
\hline india post $8 / 31$ & 6 & -0.36 & -0.04 & -2.87 & 1 & 0 & 1.53 & 1 & 0 & 0 & 88 \\
\hline italy post $11 / 34$ & 1 & -0.19 & 0.42 & -3.56 & 1 & 1 & 3.39 & 0 & 1 & 0 & 49 \\
\hline japan post $11 / 31$ & 3 & -0.09 & 0.16 & -4.30 & 1 & 1 & 7.71 & 0 & 1 & 0 & 85 \\
\hline romania post $12 / 32$ & 0 & -0.09 & -1.54 & -2.60 & 0 & 0 & 7.26 & 0 & 1 & 0 & 72 \\
\hline sweden post $8 / 31$ & 2 & -0.06 & -0.44 & -1.84 & 0 & 0 & 11.81 & 0 & 1 & 0 & 88 \\
\hline UK post8/31 & 2 & -0.10 & -0.62 & -4.00 & 1 & 1 & 6.58 & 0 & 1 & 0 & 88 \\
\hline averages & 2.64 & -0.12 & -0.42 & -2.92 & 0.55 & 0.36 & 8.30 & 0.09 & 0.82 & 0.09 & 83.00 \\
\hline
\end{tabular}

Notes:

lag

$\theta$

tstat $\theta$

sig at 0

sig at 1

half-life

\#obs lag chosen based on Akaike information criteria

the adjustment speed to shocks in the levels relationship

the levels relationship

the t-stat on the adjustment speed which is used to determine the signficiance of the levels relationship

signifies whether we can reject no levels relationship if we assume stationary data

signifies whether we can reject no levels relationship if we assume non-stationary data

the half-life of the shock based on the adjustment speed

number of observations for the episode 
Table 9d. De Facto Open Capital Market Pegs

\begin{tabular}{|c|c|c|c|c|c|c|c|c|c|c|c|}
\hline & lag chosen & $\theta$ & $\gamma$ & tstat $\theta$ & sig at 0 & sig at 1 & half-life & $<3$ & 3 to 12 & $>12$ & \#obs \\
\hline Austria 1/24-9/31 & 5 & -0.03 & 1.15 & -1.36 & 0 & 0 & 20.04 & 0 & 0 & 1 & 90 \\
\hline Belgium 8/27 - 2/33 & 0 & -0.12 & 0.57 & -2.00 & 0 & 0 & 5.33 & 0 & 1 & 0 & 67 \\
\hline Czech 2/27 - 9/31 & 1 & -0.14 & 0.10 & -1.46 & 0 & 0 & 4.70 & 0 & 1 & 0 & 56 \\
\hline France $8 / 28-9 / 36$ & 0 & -0.06 & 0.47 & -1.79 & 0 & 0 & 11.40 & 0 & 1 & 0 & 98 \\
\hline Germany $11 / 25-6 / 31$ & 0 & -0.21 & 0.15 & -3.89 & 1 & 1 & 2.88 & 1 & 0 & 0 & 68 \\
\hline Hungary $11 / 26-6 / 31$ & 6 & -0.38 & 0.87 & -3.45 & 1 & 1 & 1.45 & 1 & 0 & 0 & 56 \\
\hline India $12 / 25-8 / 31$ & 2 & -0.34 & 0.89 & -4.51 & 1 & 1 & 1.68 & 1 & 0 & 0 & 69 \\
\hline Italy $12 / 28-3 / 34$ & 1 & -0.05 & 1.50 & -1.24 & 0 & 0 & 12.98 & 0 & 0 & 1 & 64 \\
\hline Netherlands $10 / 25-9 / 36$ & 2 & -0.22 & 1.00 & -3.21 & 1 & 0 & 2.82 & 1 & 0 & 0 & 132 \\
\hline Sweden $1 / 26-8 / 31$ & 0 & -0.26 & 0.53 & -2.72 & 0 & 0 & 2.32 & 1 & 0 & 0 & 67 \\
\hline Switzerland $8 / 25-8 / 36$ & 1 & -0.05 & 0.44 & -1.85 & 0 & 0 & 14.09 & 0 & 0 & 1 & 134 \\
\hline United Kingdom 1/26 - 8/ & 0 & -0.12 & 0.16 & -1.37 & 0 & 0 & 5.52 & 0 & 1 & 0 & 68 \\
\hline Switzerland (orig) $8 / 25$ - & 3 & -0.06 & 0.14 & -2.25 & 0 & 0 & 10.65 & 0 & 1 & 0 & 134 \\
\hline averages & 1.64 & -0.17 & 0.67 & -2.46 & 0.36 & 0.27 & 6.71 & 0.45 & 0.27 & 0.27 & 79.18 \\
\hline
\end{tabular}

\footnotetext{
Notes:

lag

$\theta$

tstat $\theta$

sig at 0

sig at 1

half-life

\#obs

lag chosen based on Akaike information criteria

the adjustment speed to shocks in the levels relationship

the levels relationship

the t-stat on the adjustment speed which is used to determine the signficiance of the levels relationship

signifies whether we can reject no levels relationship if we assume stationary data

signifies whether we can reject no levels relationship if we assume non-stationary data

the half-life of the shock based on the adjustment speed

number of observations for the episode
} 


\section{Table 9e. De Facto other regimes}

\begin{tabular}{|c|c|c|c|c|c|c|c|c|c|c|c|}
\hline & lag chosen & $\theta$ & $\gamma$ & tstat $\theta$ & sig at 0 & sig at 1 & half-life & $<3$ & 3 to 12 & $>12$ & \#obs \\
\hline \multicolumn{12}{|l|}{ closed nonpegs } \\
\hline Belgium 1/20 - 7/26 & 6 & 0.03 & -1.27 & 0.43 & 0 & 0 & -27.00 & 1 & 0 & 0 & 79 \\
\hline Japan 12/23 - 4/27 & 5 & 0.07 & -4.01 & 1.01 & 0 & 0 & -10.24 & 1 & 0 & 0 & 41 \\
\hline United Kingdom 1/20 - 11 & 0 & -0.12 & 0.92 & -1.86 & 0 & 0 & 5.47 & 0 & 1 & 0 & 59 \\
\hline \multicolumn{12}{|l|}{ closed pegs } \\
\hline Bulgaria 1/28 - 3/33 & 0 & -0.10 & 0.90 & -1.84 & 0 & 0 & 6.38 & 0 & 1 & 0 & 62 \\
\hline Germany $8 / 34$ - 12/38 & 7 & -0.08 & 0.36 & -2.33 & 0 & 0 & 7.90 & 0 & 1 & 0 & 53 \\
\hline Romania $6 / 29$ - 3/33 & 0 & -0.16 & 0.91 & -2.14 & 0 & 0 & 4.03 & 0 & 1 & 0 & 46 \\
\hline \multicolumn{12}{|l|}{ open nonpegs } \\
\hline India $9 / 31-11 / 34$ & 3 & -0.49 & 0.62 & -3.57 & 1 & 1 & 1.03 & 1 & 0 & 0 & 39 \\
\hline Italy $1 / 22$ - 11/27 & 1 & -0.03 & -1.86 & -1.47 & 0 & 0 & 24.41 & 0 & 0 & 1 & 69 \\
\hline Sweden 9/31 - 11/34 & 0 & -0.07 & 0.47 & -0.76 & 0 & 0 & 10.15 & 0 & 1 & 0 & 39 \\
\hline United Kingdom 9/31 - 11 & 2 & -0.09 & -1.20 & -1.21 & 0 & 0 & 7.62 & 0 & 1 & 0 & 39 \\
\hline
\end{tabular}

\footnotetext{
Notes:

lag

$\theta$

tstat $\theta$

sig at 0

sig at 1

half-life

\#obs

lag chosen based on Akaike information criteria

the adjustment speed to shocks in the levels relationship

the levels relationship

the t-stat on the adjustment speed which is used to determine the signficiance of the levels relationship

signifies whether we can reject no levels relationship if we assume stationary data

signifies whether we can reject no levels relationship if we assume non-stationary data

the half-life of the shock based on the adjustment speed

number of observations for the episode
} 


\section{Table 9f. French episodes with the US as a base interest rate}

\begin{tabular}{|c|c|c|c|c|c|c|c|c|c|c|c|}
\hline & lag chosen & $\theta$ & $\gamma$ & tstat $\theta$ & sig at 0 & sig at 1 & half-life & $<3$ & 3 to 12 & $>12$ & \#obs \\
\hline open peg / de jure peg & & & & & & & & & & & \\
\hline $\begin{array}{l}\text { France } 8 / 28-9 / 36 \\
\text { closed nonpeg }\end{array}$ & 7 & -0.06 & -0.41 & -1.02 & 0 & 0 & 11.40 & 0 & 1 & 0 & 98 \\
\hline France $1 / 22-11 / 26$ & 0 & -0.08 & -1.28 & -1.41 & 0 & 0 & 8.42 & 0 & 1 & 0 & 58 \\
\hline
\end{tabular}

$\begin{array}{ll}\text { Notes: } & \text { lag chosen based on Akaike information criteria } \\ \text { lag } & \text { the adjustment speed to shocks in the levels relationship } \\ \theta & \text { the levels relationship } \\ \gamma & \text { the t-stat on the adjustment speed which is used to determine the signficiance of the levels relationship } \\ \text { tstat } \theta & \text { signifies whether we can reject no levels relationship if we assume stationary data } \\ \text { sig at } 0 & \text { signifies whether we can reject no levels relationship if we assume non-stationary data } \\ \text { sig at } 1 & \text { the half-life of the shock based on the adjustment speed } \\ \text { half-life } & \text { number of observations for the episode } \\ \text { \#obs } & \end{array}$


Figure 1a - United States' Interest Rate in the Interwar Years

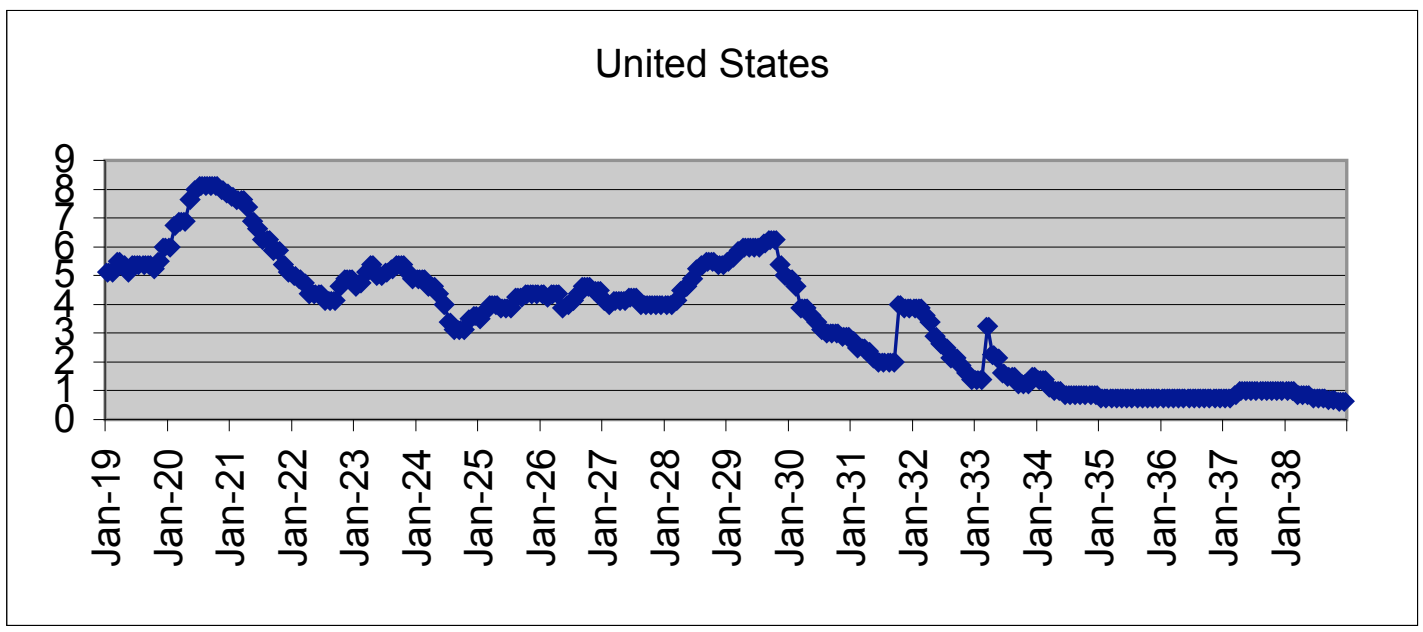

Source: Global Financial Database

Figure 1b - French Interest Rate in the Interwar Years

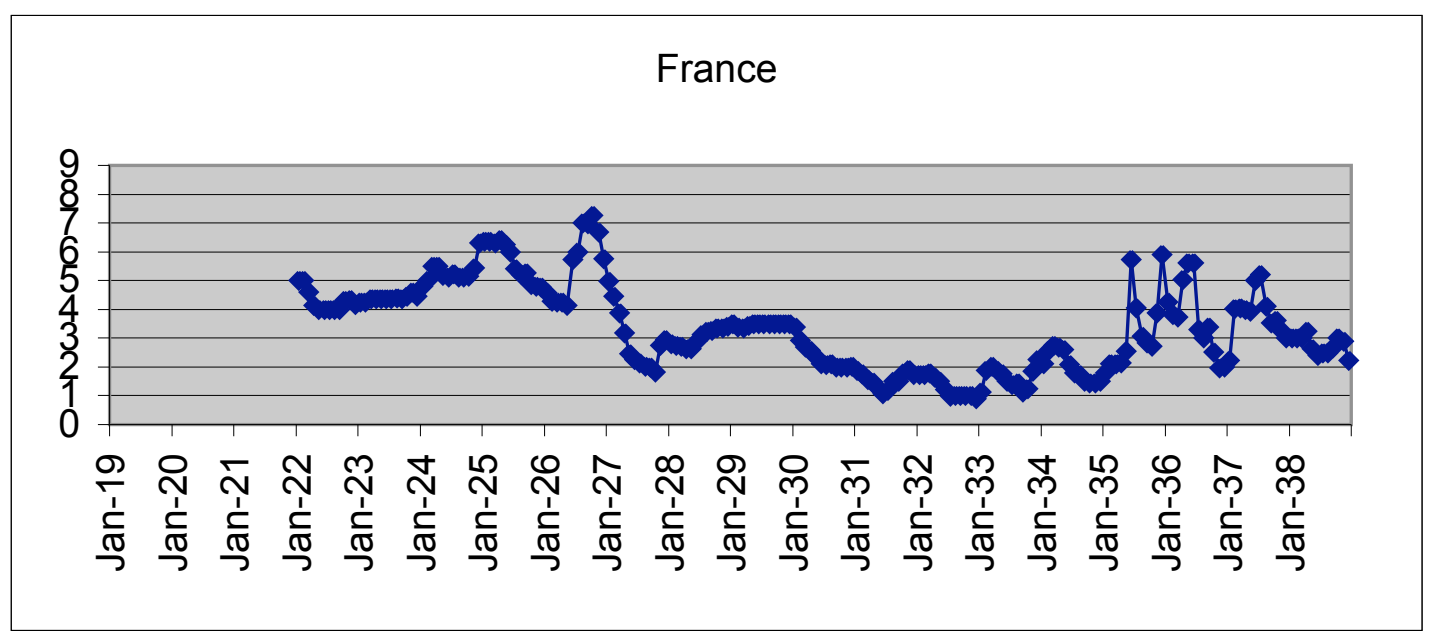

Source: Global Financial Database 
Figure 1c - "Gold Interest Rate" in the Interwar Years

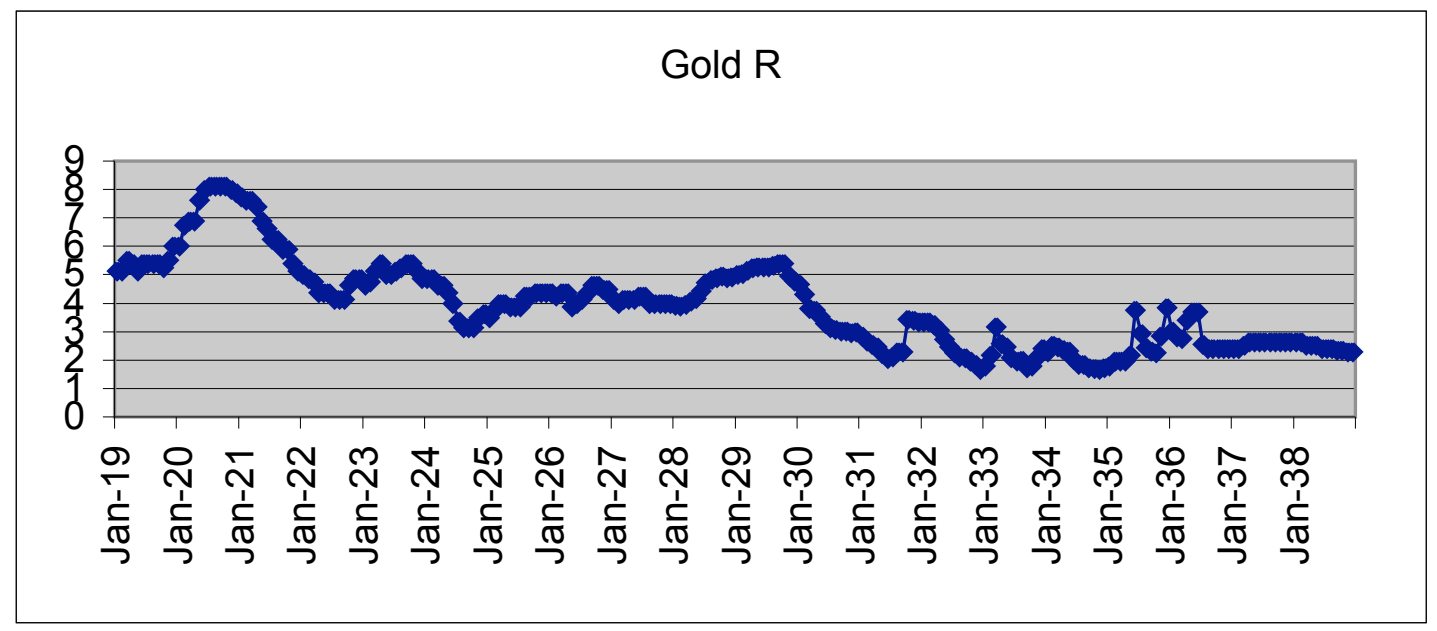

Source: Global Financial Database and author's calculations (described in text)

Figure 1d - United Kingdom Interest Rate in the Classical Gold Standard

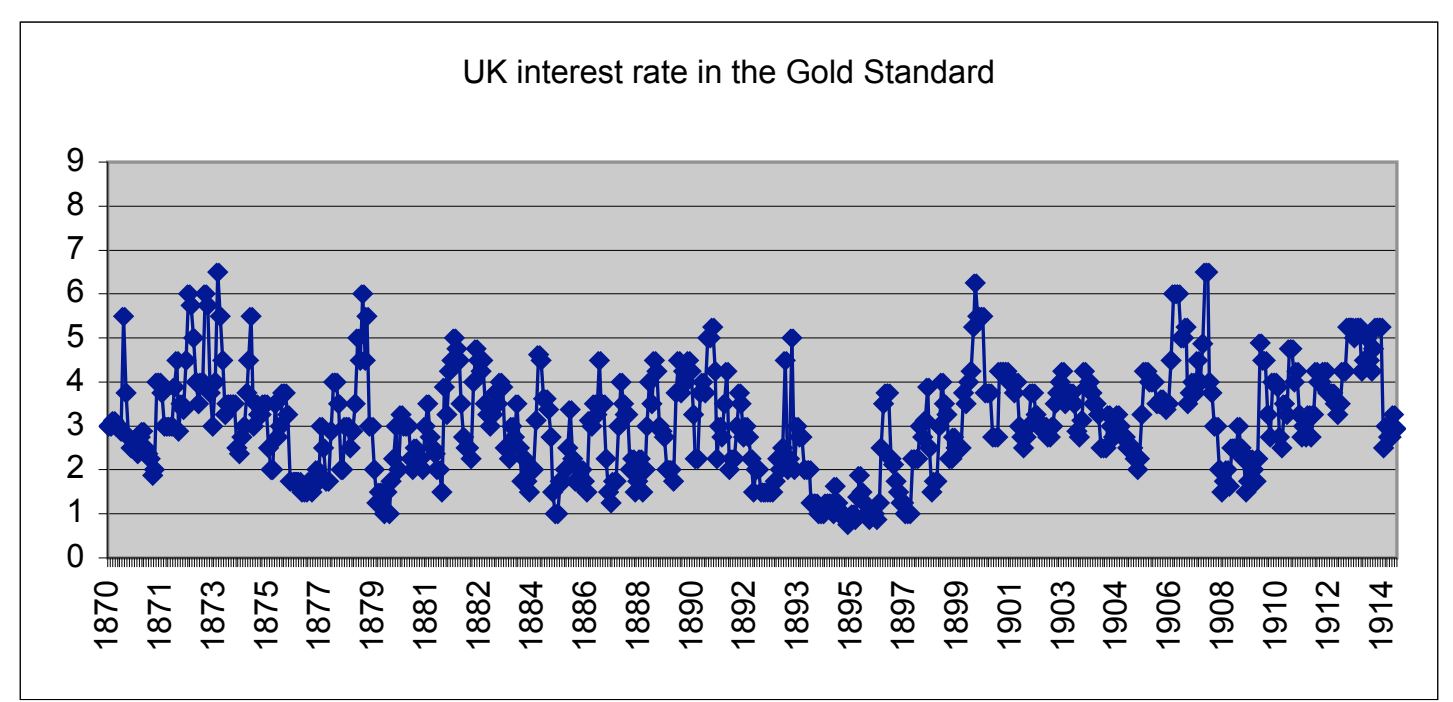

Source: Neal and Weidenmier (2003) 